\title{
Estudo polínico das espécies de Aquifoliaceae, Euphorbiaceae, Lecythidaceae, Malvaceae, Phytolaccaceae e Portulacaceae ocorrentes na restinga da Ilha do Cardoso (Cananéia, SP, Brasil)
}

\author{
MARIA AMÉLIA V. CRUZ-BARROS ${ }^{1,2}$, ANGELA M.S. CORRÊA ${ }^{1}$ e \\ HIROKO MAKINO-WATANABE ${ }^{1}$
}

(recebido: 12 de maio de 2005; aceito: 26 de janeiro de 2006)

\begin{abstract}
Pollen studies of Aquifoliaceae, Euphorbiaceae, Lecythidaceae, Malvaceae, Phytolaccaceae and Portulacaceae, ocurring in "Ilha do Cardoso (Cananéia, SP, Brasil)"). The Cardoso Island with 22,500 ha is situated in Cananéia municipality, State of São Paulo, Brazil ( $25^{\circ} 03^{\prime} 05^{\prime \prime}-25^{\circ} 18^{\prime} 18^{\prime \prime} \mathrm{S}$ and $\left.47^{\circ} 53^{\prime} 48^{\prime \prime}-48^{\circ} 05^{\prime} 42^{\prime \prime} \mathrm{W}\right)$. This study aimed to characterize the pollen morphology of 20 species belonging to the families Aquifoliaceae, Euphorbiaceae, Lecythidaceae, Malvaceae, Phytolaccaceae and Portulacaceae (one of them with two varieties), ocurring in "restinga" of Cardoso Island. Pollen grains were obtained from Herbário do Estado "Maria Eneyda P. Kauffman Fidalgo" (SP) collections. The pollen material was acetolysed, measured and photographed by light microscopy, and scanning electron microscopy. Pollen grains of the examined families are inaperturate, 3-colpate, 3-colporate, pantocolpate and pantoporate; exine psilate, rugulate, reticulate, clavate, Croton-pattern, echinate.
\end{abstract}

Key words - Cardoso Island, pollen, "restinga"

RESUMO - (Estudo polínico das espécies de Aquifoliaceae, Euphorbiaceae, Lecythidaceae, Malvaceae, Phytolaccaceae e Portulacaceae ocorrentes na restinga da Ilha do Cardoso (Cananéia, SP, Brasil)). A Ilha do Cardoso ocupa uma área de cerca de 22.500 ha no Município de Cananéia, litoral Sul do Estado de São Paulo, Brasil, entre os paralelos 25 03'05" - 25 '18' $18^{\circ}$ "S e $47^{\circ} 53^{\prime} 48^{\prime \prime}$ - 48 $05^{\prime} 42^{\prime \prime} \mathrm{W}$. Visando caracterizar morfologicamente os grãos de pólen de espécies ocorrentes na vegetação de restinga da Ilha do Cardoso, foram estudadas 20 espécies (uma delas incluindo duas variedades) pertencentes as famílias Aquifoliaceae, Euphorbiaceae, Lecythidaceae, Malvaceae, Phytolaccaceae e Portulacaceae. Os materiais polínicos foram obtidos a partir de exsicatas depositadas no Herbário do Estado "Maria Eneyda P. Kauffman Fidalgo", (SP). Os grãos de pólen foram acetolisados, medidos e fotografados sob microscopia de luz e microscopia eletrônica de varredura. As famílias estudadas apresentaram grãos de pólen que variaram quanto à abertura, desde inaperturados, 3-colpados, 3-colporados, pantocolpados a pantoporados e, quanto à escultura da exina, desde psilados, rugulados, reticulados, clavados, padrão-Croton a espinhosos.

Palavras-chave - Ilha do Cardoso, pólen, restinga

\section{Introdução}

A Ilha do Cardoso ocupa uma área de cerca de 22.500 ha no Município de Cananéia, litoral Sul do Estado de São Paulo, entre os paralelos $25^{\circ} 03^{\prime} 05^{\prime \prime}$ $25^{\circ} 18^{\prime} 18^{\prime \prime} \mathrm{S}$ e os meridianos $47^{\circ} 53^{\prime} 48^{\prime \prime}$ - $48^{\circ} 05^{\prime} 42^{\prime \prime} \mathrm{W}$. Apresenta forma bastante irregular com topografia predominantemente montanhosa, atingindo, na sua região central, a altitude de mais de $800 \mathrm{~m}$, fazendo parte do complexo estuarino lagunar de IguapeCananéia-Paranaguá, considerado o terceiro estuário do mundo em termos de produtividade primária (Barros et al. 1991, Negreiros et al. 1974). O clima na Ilha do Cardoso é influenciado por fatores locais, como maritimidade, topografia acidentada e vegetação, podendo ser considerado como do tipo megatérmico

\footnotetext{
1. Instituto de Botânica, Caixa Postal 4005, 01061-970 São Paulo, SP, Brasil.

2. Autor para correspondência: mcruz-barros@ig.com.br
}

superúmido, sem déficit de água durante o ano, com temperatura média anual de $21,2{ }^{\circ} \mathrm{C}$ e índice de pluviosidade anual de mais de $3.000 \mathrm{~mm}$ (Funari et al. 1987).

Devido à configuração geográfica complexa, à alta pluviosidade e às caracterísiticas dos solos que favorecem o escoamento sub-superficial, a Ilha do Cardoso apresenta condições ecológicas muito variadas, propiciando o estabelecimento de biótopos diferenciados tais como: floresta, mangue e restinga. De acordo com Noffs \& Baptista Noffs (1982a), identificam-se cinco formações vegetais naturais na Ilha: vegetação pioneira de dunas, vegetação de restinga, floresta pluvial tropical da planície litorânea, floresta pluvial tropical da Serra do Mar e vegetação de mangue, além das diferentes formações naturais tratadas conjuntamente como "vegetação secundária". Segundo Barros et al. (1991), cada uma das formações vegetais apresenta características peculiares quanto à composição florística, fisionomia e distribuição. 
A vegetação de restinga cobre a maior parte da planície arenosa da Ilha do Cardoso e apresenta-se como um complexo de diferentes comunidades vegetais (Barros et al. 1991).

Ao estudar a vegetação da Ilha, De Grande \& Lopes (1981) citaram quatro subtipos na restinga: uma faixa de restinga recente, rala e de pequeno porte; a restinga de mirtáceas; uma restinga de porte mais elevado onde predomina Clusia e uma vegetação de transição para a mata.

Este trabalho teve como objetivo caracterizar morfologicamente os grãos de pólen de famílias já estudadas taxonomicamente e publicadas na Flora Fanerogâmica da Ilha do Cardoso (Barros 1992, Chiea \& Romaniuc Neto 1992, Chiea \& Silva 1992, Cordeiro 1992 e Furlan 1992 a,b). Foram selecionadas as famílias: Aquifoliaceae, Lecythidaceae, Malvaceae, Phytolaccaceae, Portulacaceae e Euphorbiaceae que ocorrem na vegetação da restinga da Ilha do Cardoso que juntas perfazem um total de 20 espécies, uma delas incluindo duas variedades. Os dados obtidos servirão para complementar os estudos taxonômicos das espécies e serão de grande valia para estudos que visam a manutenção do equilíbrio ecológico, o desenvolvimento de estratégias para a conservação da biodiversidade e o uso sustentável dos recursos naturais. Poderão auxiliar ainda, nos estudos de interpretação da sucessão da flora devido aos avanços e recuos do mar, alterações climáticas e ecológicas, pesquisas arqueológicas e de prospecção de petróleo etc., através da análise dos grãos de pólen contidos nos sedimentos de solo.

\section{Material e métodos}

O material examinado foi obtido de exsicatas depositadas no Herbário do Estado "Maria Eneyda P. Kauffman Fidalgo", do Instituto de Botânica (SP).

As plantas da restinga foram selecionadas das listas de De Grande \& Lopes (1981), Barros et al. (1991), Barros (1992), Chiea \& Romaniuc Neto (1992), Chiea \& Silva (1992), Cordeiro (1992) e Furlan (1992a, b).

Para cada espécie procurou-se examinar, sempre que possível, mais de um espécime. O espécime assinalado com um asterisco $(*)$ na relação de espécies estudadas, representa o material padrão, o qual foi utilizado para as descrições e ilustrações polínicas. As lâminas com o material polínico encontram-se depositadas na palinoteca da Seção de Dicotiledôneas, no Instituto de Botânica de São Paulo.

Aquifoliaceae - Ilex dumosa Reissek: BRASIL. São PAULO: Cananéia, 23-XI-1982, R.D. Marassi et al. 51 (SP); 27-XI-1991, M. Sugiyama 977 (SP)*; 19-XII-1991, M. Sugiyama 987 (SP). Ilex integerrima (Vell.) Reissek: BRASIL. São PAULO:
Cananéia, 27-XI-1979, D.A. De Grande \& E.A. Lopes 325 (SP)*. Ilex theezans var. acrodonta (Reissek) Loes.: BRASIL. São Paulo: Cananéia, 1-XII-1978, D.A. De Grande \& E.A. Lopes 183 (SP)*; 27-XI-1991, M. Sugiyama 978 (SP). Ilex theezans var. grandifolia Loes.: BRASIL. SÃo PaUlo: Cananéia, 30-X-1991, F. Barros 232 (SP); 29-XI-1978, D.A. De Grande \& E.A. Lopes 170 (SP); 9-XI-1977, D.A. De Grande \& E.A. Lopes 3 (SP); 30-X-1985, M. Kirizawa 1527 (SP); 24-XI-1982, R.D. Marassi et al. 57 (SP)*.

Euphorbiaceae - Actinostemon concolor (Spreng.) Muell. Arg.: BRASIL. São PAULO: Cananéia, 30-X-1991, F. Barros 2344 (SP)*. Alchornea triplinervia (Spreng.) Muell. Arg.: BRASIL. São PAulo: Cananéia, 14-XI-1979, D.A. De Grande \& E.A. Lopes 347 (SP)*; 8-X-1980, E. Forero et al. 8673 (SP); 2-XII-1990, F. Barros 1974 (SP). Aparisthmium cordatum (A. Juss.) Baill.: BRASIL. SÃo Paulo: Cananéia, 6-XII-1985, M.M.R.F. Melo 589 (SP)*. Croton macrobothrys Baill.: BRASIL. São PAULO: Cananéia, 24-IX-1982, A. Custodio Filho et al. 915 (SP)*; 26-X-1982, R.D.C. Xavier 16 (SP). Dalechampia ficifolia Lam.: BRASIL. SÃo PAULO: Cananéia, 28-XI-1974, J. Mattos 16104 (SP)*; 8-X-1980, F. Barros 469 (SP); 16-XI-1979, D.A. De Grande \& E.A. Lopes 350 (SP); 8-X-1980, E. Forero et al. 8615 (SP); 3-XII-1985, I.C.C. Macedo et al. 80 (SP); 13-X-1986, I. Cordeiro et al. 350 (SP). Euphorbia insulana Vell.: BRASIL. SÃo PAULO: Cananéia, 6-IV-1982, C.R.F. Guedes 12 (SP)*; 6-II-1986, T.M. Cerati et al. 347 (SP); 26-VIII-1988, I. Cordeiro et al. 499 (SP). Pausandra morisiana (Casar.) Radlk.: BRASIL. São PAULo: Cananéia, 7-X-1980, E. Forero et al. 858 (SP)*. Pera glabrata (Schott) Baill.: BRASIL. S̃̃o PAULO: Cananéia, s.d., M.M.R.F. Melo et al. 559 (SP)*, 11-II-1979, D.A. De Grande \& E.A. Lopes 215 (SP); 8-XII-1987, M. Kirizawa 1975 (SP); 7-IV-1988, F. Barros 1499 (SP). Sebastiania corniculata (Vahl.) Muell. Arg.: BRASIL. São PAULO: Cananéia, 14-X-1986, G.L. Webster et al. 25547 (SP)*; 5-IV-1982, M.R.O. Santos et al. 6 (SP); 8-X-1980, E. Forero et al. 8630 (SP). Tetrorchidium rubrivenium Poepp.: BRASIL. São Paulo: Cananéia, 24-VIII-1988, I. Cordeiro et al. 476 (SP)*.

Lecythidaceae - Cariniana estrellensis (Raddi) O. Ktze.: BRASIL. São PAULO: Cananéia, 5-XII-1985, Barros 1228 (SP)*; 25-IV-1989, F. Barros \& P. Martuscelli 1635 (SP); 24-V-1983, S.L. Jung-Mendaçolli \& E.A. Lopes 550 (SP).

Malvaceae - Talipariti tiliaceum var. pernambucense (Arruda) Frixell: BRASIL. São PAuLo: Cananéia, 18-I-1978, D.A. De Grande \& E.A. Lopes 18 (SP)*, 12-XII-1980, A. Custodio Filho 497 (SP); 7-IV-1982, A.M. Fortes et al. 9 (SP); 14-IX1977, O. Yano s.n. (SP154662). Sida rhombifolia L.: BRASIL. SÃo PAulo: Cananéia, 29-XI-1974, Mattos 16721 (SP)*; 21VIII-1979, C.F.S. Muniz \& A. Custodio Filho 54 (SP). Urena lobata L.: BRASIL. São PAULO: Cananéia, 29-XI-1974, J. Mattos 16254 (SP)*; 21-VI-1977, M. Goes 13 (SP).

Phytolaccaceae - Petiveria alliacea L.: BRASIL. São PAULO: Cananéia, 19-IV-1983, M. Kirizawa et al. 968 (SP)*. Phytolacca thyrsiflora Fenzl ex Schm.: BRASIL. São PAULO: Cananéia, 15-III-1978, D.A. De Grande \& E.A.Lopes s.n. (SP161711)*. 
Portulacaceae - Portulaca umbraticola H.B.K.: BRASIL. São PAulo: Cananéia, 8-X-1980, E. Forero et al. 8627 (SP)*.

O material polínico, para análise em microscopia de luz, foi preparado pela técnica de acetólise (Erdtman 1960). Os grãos de pólen foram medidos dentro do prazo máximo de uma semana (Melhem \& Matos 1972; Salgado-Labouriau 1973). No material padrão as medidas dos diâmetros foram feitas em 25 grãos de pólen, tomados ao acaso e distribuídos em pelo menos três lâminas (Salgado-Labouriau et al. 1965). Para outros caracteres como abertura, espinho, distância entre espinhos, espessura e ornamentação da exina foram feitas, sempre que possível, 10 medidas, o mesmo ocorrendo para as medidas dos diâmetros dos grãos de pólen dos materiais de comparação; neste caso calculou-se a média aritmética.

As imagens dos grãos de pólen foram obtidas através de microscópio de luz (ML), Olympus - modelo BX-202, com sistema de captação de imagem Sony, empregando-se o software Image Pró-Plus na versão 3 para Windows.

Para análise em microscopia eletrônica de varredura (MEV), os grãos de pólen não acetolisados, foram espalhados diretamente sobre suportes metálicos "stubs", previamente recobertos com adesivo, sendo em seguida, metalizados e analisados sob microscópio Philips XL, 20, S/W versão 5.21.

Os têrmos polínicos utilizados nas descrições dos grãos de pólen baseiam-se no glossário de Punt et al. (1999) enquanto que a classe de tamanho e a forma dos grãos de pólen estão de acordo com Barth \& Melhem (1988).

\section{Resultados}

Os grãos de pólen estudados pertencem a 20 espécies (uma delas incluindo duas variedades) de seis famílias distintas, de modo que os resultados de cada família serão tratados separadamente.

Família Aquifoliaceae (figuras 1-5; tabelas 1, 5).

Ilex dumosa Reissek (figuras 1,2) - Grãos de pólen pequenos a médios; isopolares; âmbito circular; prolatoesferoidais; 3-colporados, colpos largos, curtos, endoaberturas lalongadas, operculadas; exina clavada, clavas de diferentes tamanhos, sexina mais espessa que a nexina.

Ilex integerrima (Vell.) Reissek (figuras 3, 4) Grãos de pólen médios; isopolares; âmbito circular; subprolatos; 3-colporados, colpos largos, curtos, recobertos por membrana ornamentada, endoaberturas lalongadas de difícil visualização; exina clavada, clavas maiores no pólo e mesocólporo, diminuindo de tamanho em direção às aberturas, sexina mais espessa que a nexina. Sob MEV, os grãos de pólen não acetolisados, apresentaram forma nitidamente oblata, conforme mostra a figura 4.
Ilex theezans var. acrodonta (Reissek) Loes. Grãos de pólen médios; isopolares; âmbito circular; prolato-esferoidais; 3-colporados, colpos largos, curtos, endoaberturas lalongadas; exina clavada, clavas de diferentes tamanhos, sexina mais espessa que a nexina.

Ilex theezans var. grandifolia Loes. (figura 5) Grãos de pólen médios; isopolares; âmbito circular; prolato-esferoidais; 3-colporados, colpos largos, curtos, constritos, endoaberturas lalongadas; exina clavada, clavas de diferentes tamanhos, sexina mais espessa que a nexina. Na figura 5, observa-se sob MEV, um grão de pólen que parece ter sofrido um amassamento na região equatorial durante a preparação, tornando-o prolato.

Família Euphorbiaceae (figuras 6-35; tabelas 2, 3, 5).

Actinostemon concolor (Spreng.) Muell. Arg. (figuras 6-9) - Grãos de pólen médios; isopolares; âmbito subcircular; prolato-esferoidais; 3-colporados, colpos longos, estreitos, com margem, recobertos por opérculo, endoaberturas circulares a lolongadas, com opérculo; exina microrreticulada, simplescolumelada, sexina mais espessa que a nexina.

Alchornea triplinervia (Spreng.) Muell. Arg. (figuras 10-12) - Grãos de pólen pequenos; isopolares; âmbito subtriangular; prolato-esferoidais; 3-colporados, colpos longos, estreitos, recobertos por opérculo, endoaberturas lalongadas; exina psilada sob ML e rugulada sob MEV, sexina mais espessa que a nexina.

Aparisthmium cordatum (A. Juss.) Baill. (figuras 13-15) - Grãos de pólen pequenos a médios; isopolares; âmbito triangular; oblato-esferoidais; 3-colporados, colpos estreitos, recobertos por opérculo, endoaberturas lalongadas; exina rugulada sob ML e rugulado-perfurada sob MEV, sexina mais espessa que a nexina.

Croton macrobothrys Baill. (figuras 16, 17) - Grãos de pólen grandes; apolares; esféricos; inaperturados; exina com padrão-Croton na qual as unidades de ornamentação têm, predominantemente, 6-7 subunidades de ornamentação, subunidades com ápices psilados; sob MEV observa-se a presença de grânulos nos lumens das unidades, sexina mais espessa que a nexina.

Dalechampia ficifolia Lam. (figuras 18-20) Grãos de pólen médios a grandes; isopolares; âmbito circular; subprolatos; 3-colporados, colpos curtos, estreitos com margem fina e psilada, endoaberturas lalongadas, endocinguladas, com costa; exina reticulada, retículos maiores nos pólos e na região do mesocólporo, diminuindo gradativamente na região das aberturas, muros psilados, sinuosos e sobre estes, perfurações esparsas, sexina mais espessa que a nexina. 
Tabela 1. Medidas $(\mu \mathrm{m})$ dos grãos de pólen das espécies de Ilex (Aquifoliaceae) em vista equatorial e polar $(n=25)$; apocolpo, colpo, endoabertura e exina $(n=10)$. ( $\mathrm{VP}=$ vista polar; $\mathrm{VE}=$ vista equatorial; $\mathrm{P}=$ diâmetro polar; $\mathrm{E}=$ diâmetro equatorial; $\mathrm{FV}=$ faixa de variação; $\overline{\times}=$ média aritmética; $s_{\overline{\mathrm{x}}}=$ desvio padrão da média; $s=$ desvio da amostra; $\mathrm{V}=$ coeficiente de variabilidade; IC $=$ intervalo de confiança; compr. = comprimento; larg. = largura).

Table 1. Measures $(\mu \mathrm{m})$ of pollen grains of Ilex (Aquifoliaceae) in equatorial and polar views $(n=25)$; apocolpium, colpus, endoaperture and exine $(n=10)$. $(\mathrm{VP}=$ polar view; $\mathrm{VE}=$ equatorial view; $\mathrm{P}=$ polar diameter; $\mathrm{E}=$ equatorial diameter; $\mathrm{FV}=$ range, $\overline{\mathrm{x}}=$ arithmetic mean; $s_{\overline{\mathrm{x}}}=$ standard deviation of medium; $s=$ standard deviation of sample; $\mathrm{V}=$ coefficient of variability; IC $=$ confidence interval; compr. = length; larg. $=$ width $)$.

\begin{tabular}{|c|c|c|c|c|c|}
\hline \multirow[b]{2}{*}{ Grandezas } & & \multicolumn{4}{|c|}{ Espécies } \\
\hline & & I. dumosa & I. integerrima & I. theezans var. acrodonta & I. theezans var. grandifolia \\
\hline Diâmetro & FV & $22,6-29,0$ & $29,4-38,1$ & $24,8-28,9$ & $31,7-38,6$ \\
\hline \multirow{4}{*}{$\begin{array}{l}\text { Equatorial } \\
\text { (VP) }\end{array}$} & $\bar{\chi} \pm s_{\overline{\bar{x}}}$ & $25,2 \pm 0,3$ & $33,3 \pm 0,4$ & $26,9 \pm 0,2$ & $34,8 \pm 0,3$ \\
\hline & $s$ & 1,6 & 2,1 & 1,1 & 1,6 \\
\hline & V\% & 6,4 & 6,3 & 4,2 & 4,5 \\
\hline & IC $(95 \%)$ & $24,6-25,8$ & $32,5-34,1$ & $26,5-27,3$ & $34,2-35,4$ \\
\hline Diâmetro & FV & $23,3-29,5$ & - & $27,9-33,7$ & $33,4-40,7$ \\
\hline Polar & $\bar{x} \pm s_{\bar{x}}$ & $25,3 \pm 0,3$ & 37,7 & $30,3 \pm 0,2$ & $36,0 \pm 0,3$ \\
\hline (VE) & $s$ & 1,5 & - & 1,2 & 1,8 \\
\hline \multirow[t]{2}{*}{$\mathrm{V} \%$} & 6,1 & - & 3,9 & 4,9 & \\
\hline & $\mathrm{IC}(95 \%)$ & $24,7-25,9$ & - & 29,9-30,7 & $35,4-36,6$ \\
\hline Diâmetro & $\mathrm{FV}$ & $22,6-27,1$ & - & $24,1-30,3$ & $33,7-37,5$ \\
\hline Equatorial & $\bar{x} \pm s_{\bar{x}}$ & $24,4 \pm 0,2$ & 28,7 & $27,8 \pm 0,3$ & $35,4 \pm 0,2$ \\
\hline \multirow[t]{3}{*}{ (VE) } & $s$ & 1,0 & - & 1,5 & 1,1 \\
\hline & $\mathrm{V} \%$ & 4,2 & - & 5,5 & 3,2 \\
\hline & $\mathrm{IC}(95 \%)$ & $24,0-24,8$ & - & $27,2-28,4$ & $35,0-35,8$ \\
\hline $\mathrm{P} / \mathrm{E}$ & & 1,04 & 1,31 & 1,08 & 1,01 \\
\hline Apocolpia & & 5,7 & 10,7 & 6,2 & 8,1 \\
\hline \multirow[t]{2}{*}{ Colpo } & compr. & 15,2 & 23,5 & 19,7 & 23,3 \\
\hline & larg. & 7,7 & 5,1 & 5,3 & 6,2 \\
\hline \multirow[t]{2}{*}{ endoabertura } & compr. & 2,3 & - & 1,8 & 3,6 \\
\hline & larg. & 4,5 & - & 7,4 & 7,6 \\
\hline Exina & & 5,3 & 5,2 & 4,4 & 5,5 \\
\hline Sexina & & 3,0 & 3,8 & 2,9 & 3,3 \\
\hline Nexina & & 2,1 & 1,4 & 1,5 & 2,3 \\
\hline
\end{tabular}

Euphorbia insulana Vell. (figuras 21-23) - Grãos de pólen médios; isopolares; âmbito circular; prolatoesferoidais; 3-colporados, colpos longos, estreitos, com margem, endoaberturas lolongadas, pouco nítidas; exina reticulada, sexina mais espessa que a nexina.

Pausandra morisiana (Casar.) Radlk. (figuras 24, 25) - Grãos de pólen médios a grandes; apolares; esféricos; inaperturados; exina com padrão-Croton, na qual as unidades de ornamentação têm, predominantemente, 5-6 subunidades de ornamentação, subunidades com ápice psilado; sexina mais espessa que a nexina.

Pera glabrata (Schott) Baill. (figuras 26-28) Grãos de pólen pequenos; isopolares; âmbito circular; prolato-esferoidais; 3-colporados, colpos estreitos, longos, com margem e costa, endoaberturas lalongadas com margem, às vezes recobertas por opérculo; exina reticulada, heteroreticulada, simplescolumelada, sexina mais espessa que a nexina.

Sebastiania corniculata (Vahl.) Muell. Arg. (figuras 29-31) - Grãos de pólen médios; isopolares; âmbito subtriangular, lobado, prolato-esferoidais; 3-colporados, colpos longos, quase unidos nos pólos formando uma invaginação, com margem espessa, psilada, endoaberturas lalongadas, com margem; exina microrreticulada, sexina mais espessa que a nexina. $\mathrm{Na}$ região do mesocolpo (figura 29 ), a sexina se afasta da nexina, formando uma cava.

Tetrorchidium rubrivenium Poepp. (figuras 32-35) - Grãos de pólen médios; isopolares; âmbito subtriangular; suboblatos; 3-colporados, colpos curtos, 
Revista Brasil. Bot., V.29, n.1, p.145-162, jan.-mar. 2006

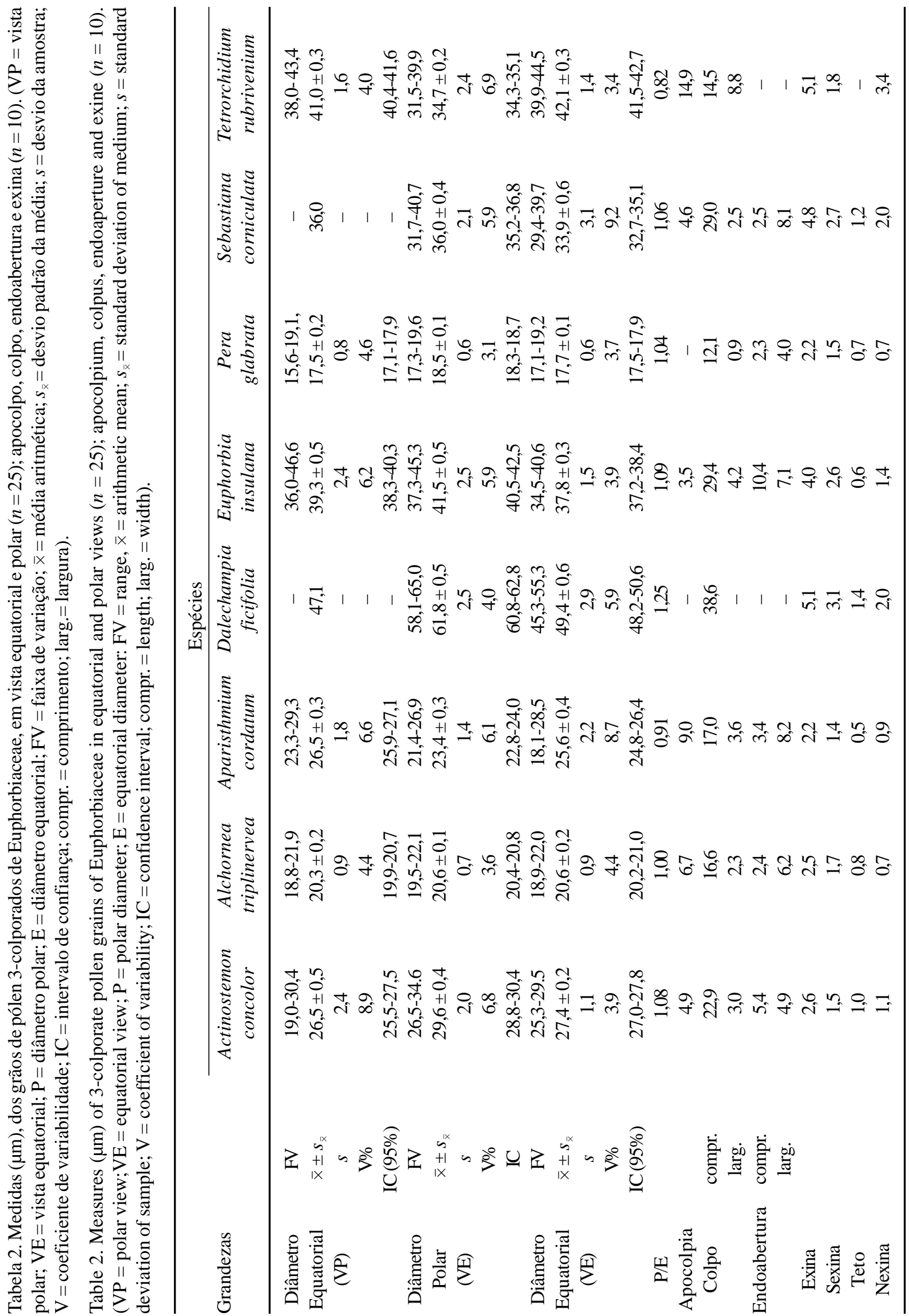



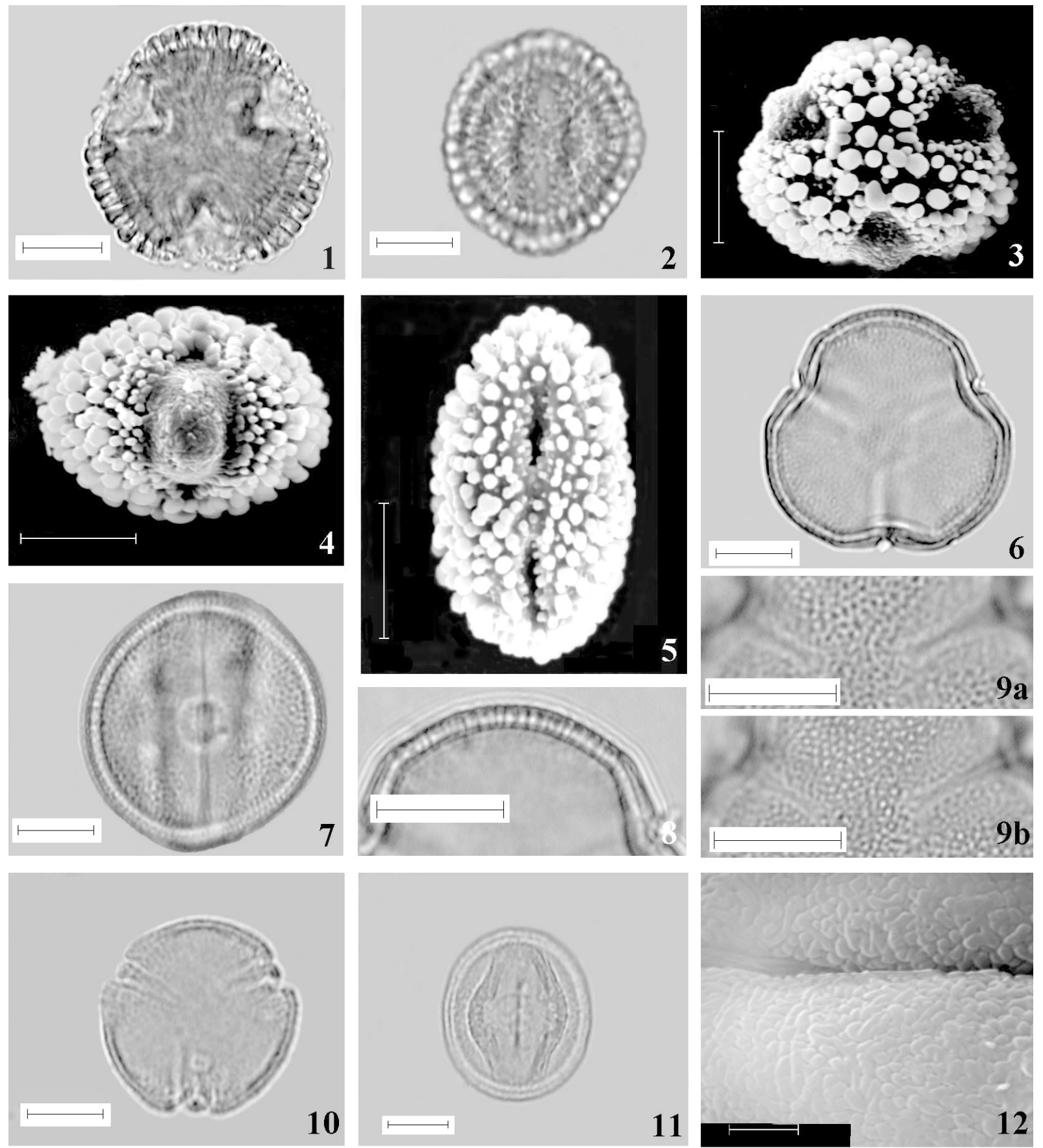

Figuras 1-12. Fotomicrografias e eletromicrografias de grãos de pólen de Aquifoliaceae (1-5) e Euphorbiaceae (6-12). 1-2. Ilex dumosa Reissek. 1. Vista polar, contorno. 2. Vista equatorial evidenciando a abertura. 3-4. I. integerrima (Vell.) Reissek. 3. Vista polar (MEV). 4. Vista equatorial mostrando a abertura (MEV). 5. I. theezans var. grandifolia Loes. Vista equatorial mostrando a abertura (MEV). 6-9. Actinostemon concolor (Spreng.) Muell. Arg. 6. Vista polar, contorno. 7. Vista equatorial evidenciando a abertura. 8. Corte óptico no pólo. 9. ML em dois níveis de focalização. 10-12. Alchornea triplinervea (Spreng.) Muell. Arg. 10. Vista polar, contorno. 11. Vista equatorial. 12. Detalhe da ornamentação (MEV). Barras $=10 \mu \mathrm{m}(1-11) ; 2 \mu \mathrm{m}(12)$.

Figures 1-12. Light and scanning electron micrographs of pollen grains of Aquifoliaceae (1-5) and Euphorbiaceae (6-12). 1-2. Ilex dumosa Reissek. 1. Polar view, outline. 2. Equatorial view showing aperture. 3-4. I. integerrima (Vell.) Reissek. 3. Polar view (SEM). 4. Equatorial view (SEM). 5. I. theezans var. grandifolia Loes. Equatorial view (SEM). 6-9. Actinostemon concolor (Spreng.) Muell. Arg. 6. Polar view, outline. 7. Equatorial view, showing aperture. 8. Polar view, optical section. 9. L.O. in high and low focus. 10-12. Alchornea triplinervea (Spreng.) Muell. Arg. 10. Polar view, outline. 11. Equatorial view. 12. Detail of ornamentation (SEM). Bars $=10 \mu \mathrm{m}(1-11) ; 2 \mu \mathrm{m}(12)$. 

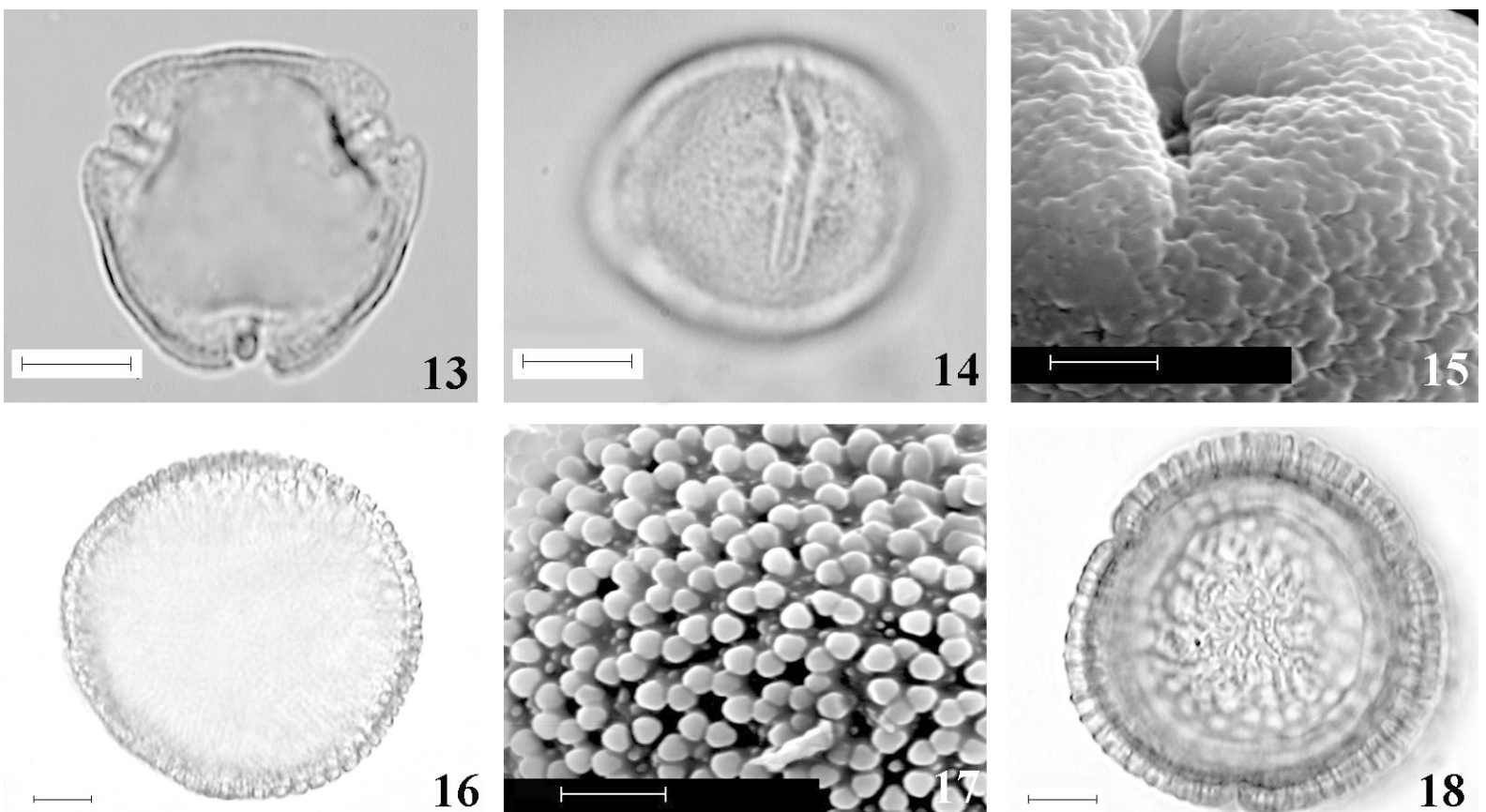

16
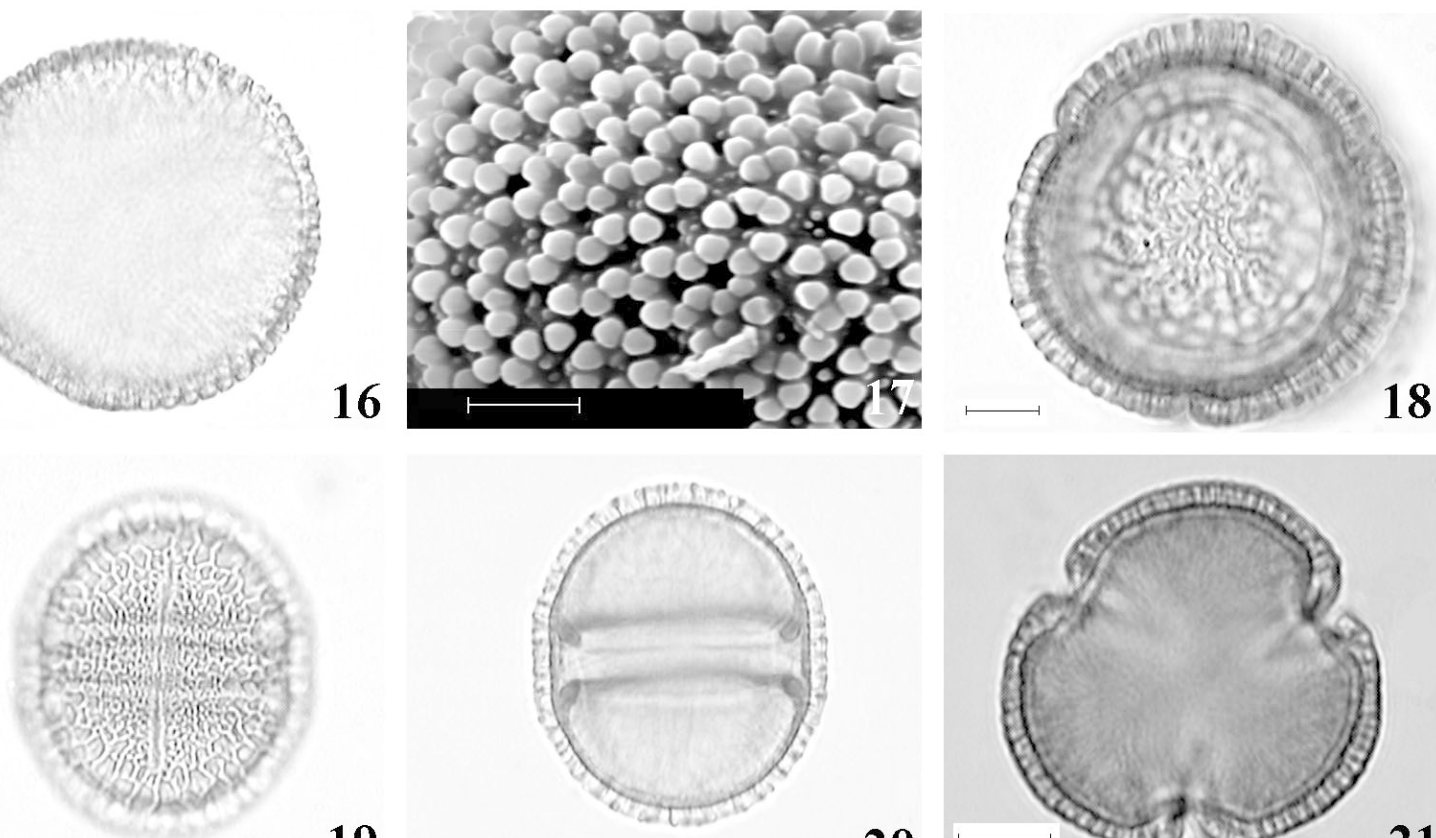

19

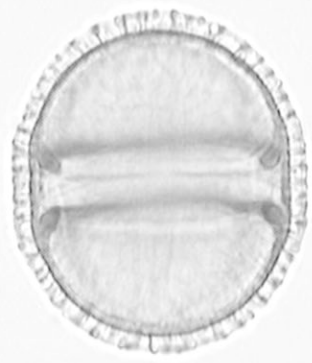

20
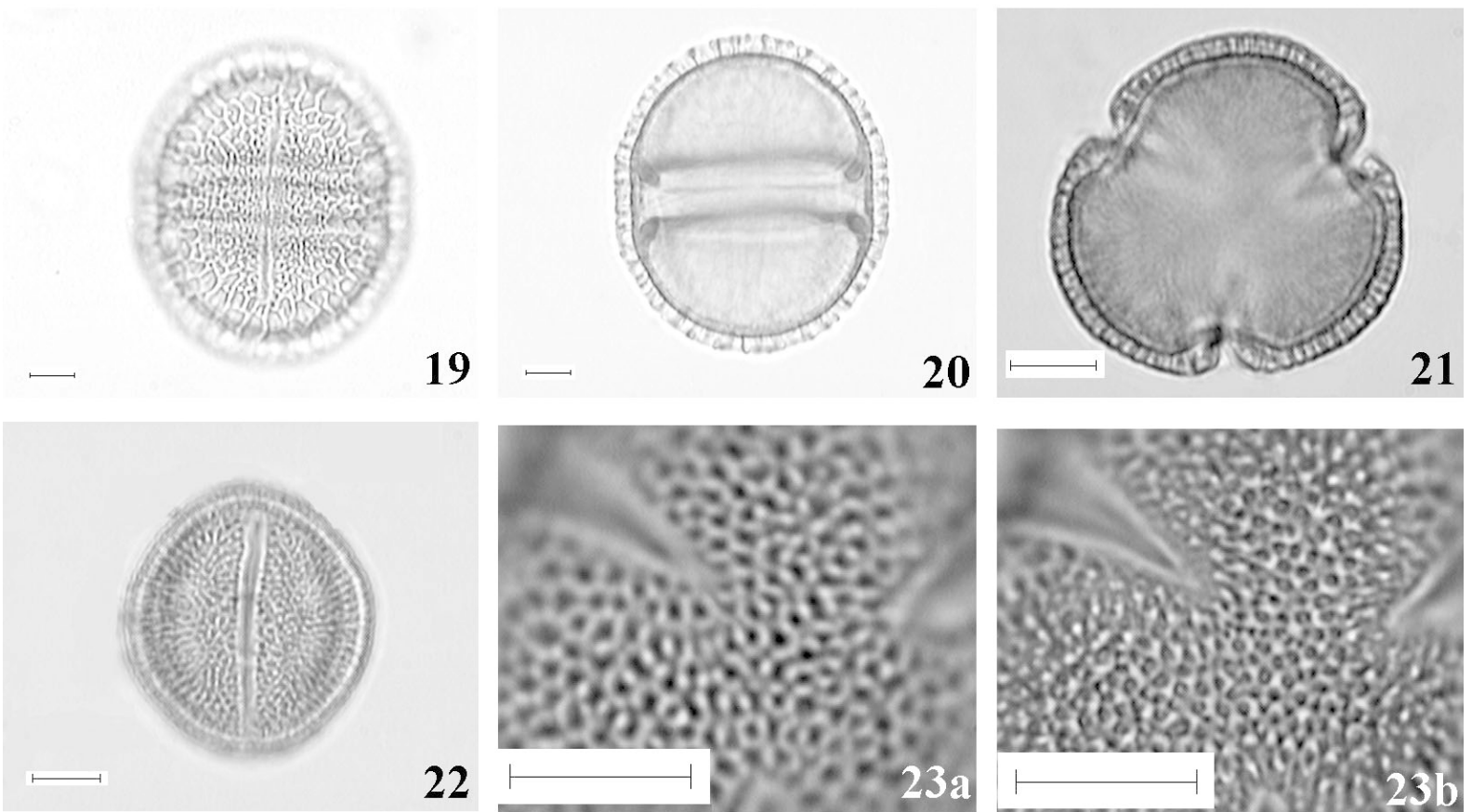

Figuras. 13-23. Fotomicrografias e eletromicrografias dos grãos de pólen de Euphorbiaceae. 13-15. Aparisthmium cordatum (A. Juss.) Baill. 13. Contorno em vista polar. 14. Vista equatorial evidenciando a abertura. 15. Detalhe da ornamentação (MEV). 16-17. Croton macrobothrys Baill. 16. Vista geral e contorno. 17. Detalhe da ornamentação (MEV). 18-20. Dalechampia ficifolia Lam. 18. Contorno em vista polar. 19. Vista equatorial evidenciando a abertura. 20. Contorno em vista equatorial. 21-23. Euphorbia insulana Vell. 21.Vista polar, corte óptico. 22. Vista equatorial, evidenciando a abertura. 23. ML em dois níveis de focalização. Barras = $10 \mu \mathrm{m}(13,14,16,18-23) ; 2 \mu \mathrm{m}(15) ; 5 \mu \mathrm{m}$ (17).

Figures 13-23. Light and scanning electron micrographs of pollen grains of Euphorbiaceae. 13-15. Aparisthmium cordatum (A. Juss.) Baill. 13. Polar view, outline. 14. Equatorial view showing aperture. 15. Detail of ornamentation (SEM). 16-17. Croton macrobothrys Baill. 16. General view, outline. 17. Detail of ornamentation (SEM). 18-20. Dalechampia ficifolia Lam. 18. Polar view, outline. 19. Equatorial view showing of aperture. 20. Equatorial view, outline. 21-23. Euphorbia insulana Vell. 21. Polar view, optical section. 22. Equatorial view showing of aperture. 23. L.O. in high and low focus. Bars $=10 \mu \mathrm{m}(13,14,16,18-23)$; $2 \mu \mathrm{m}(15) ; 5 \mu \mathrm{m}(17)$. 


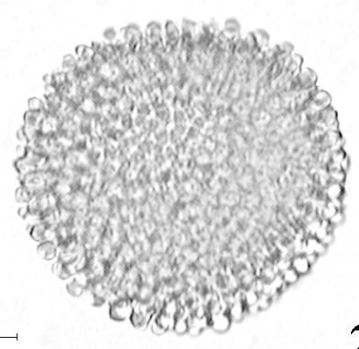

24
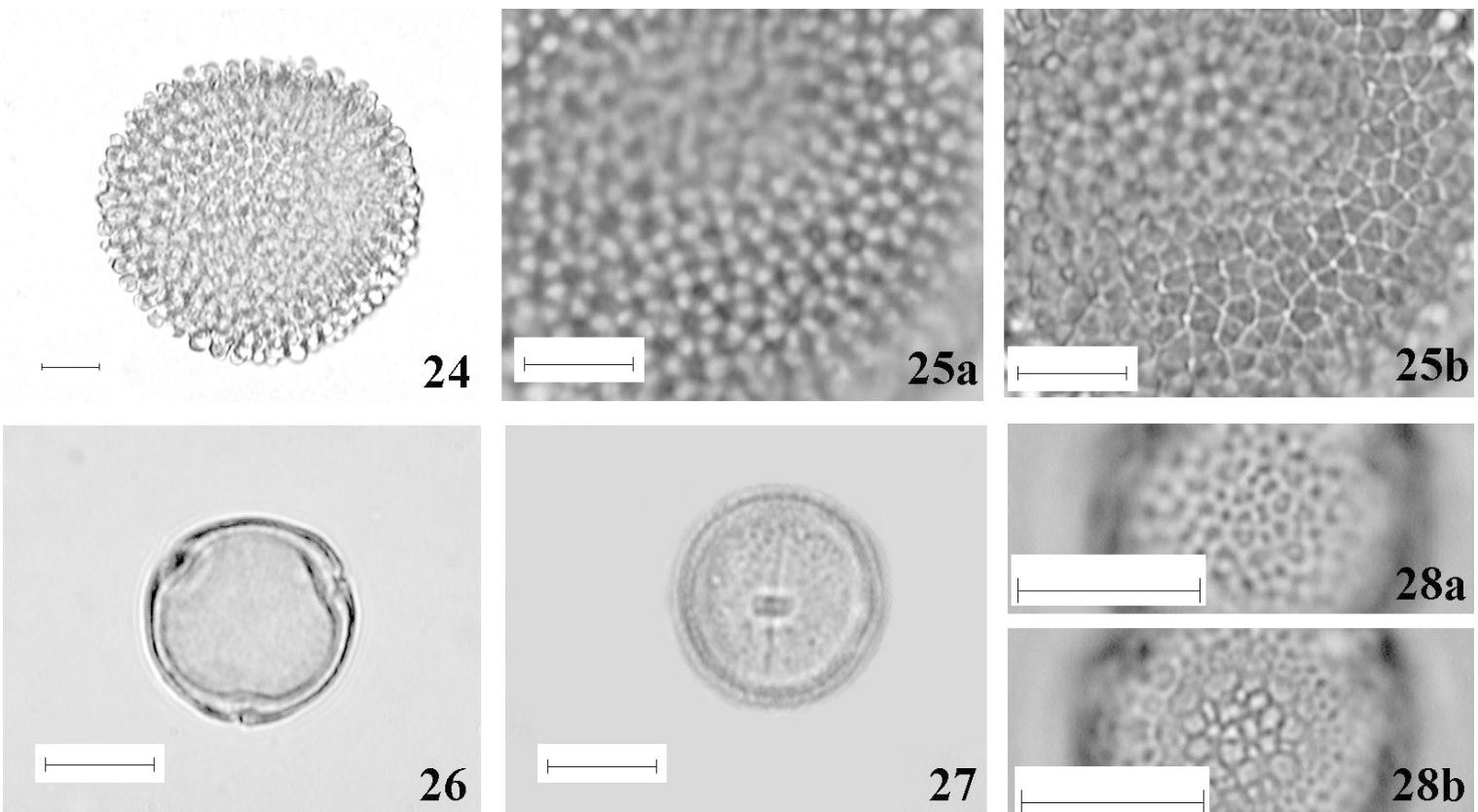

27
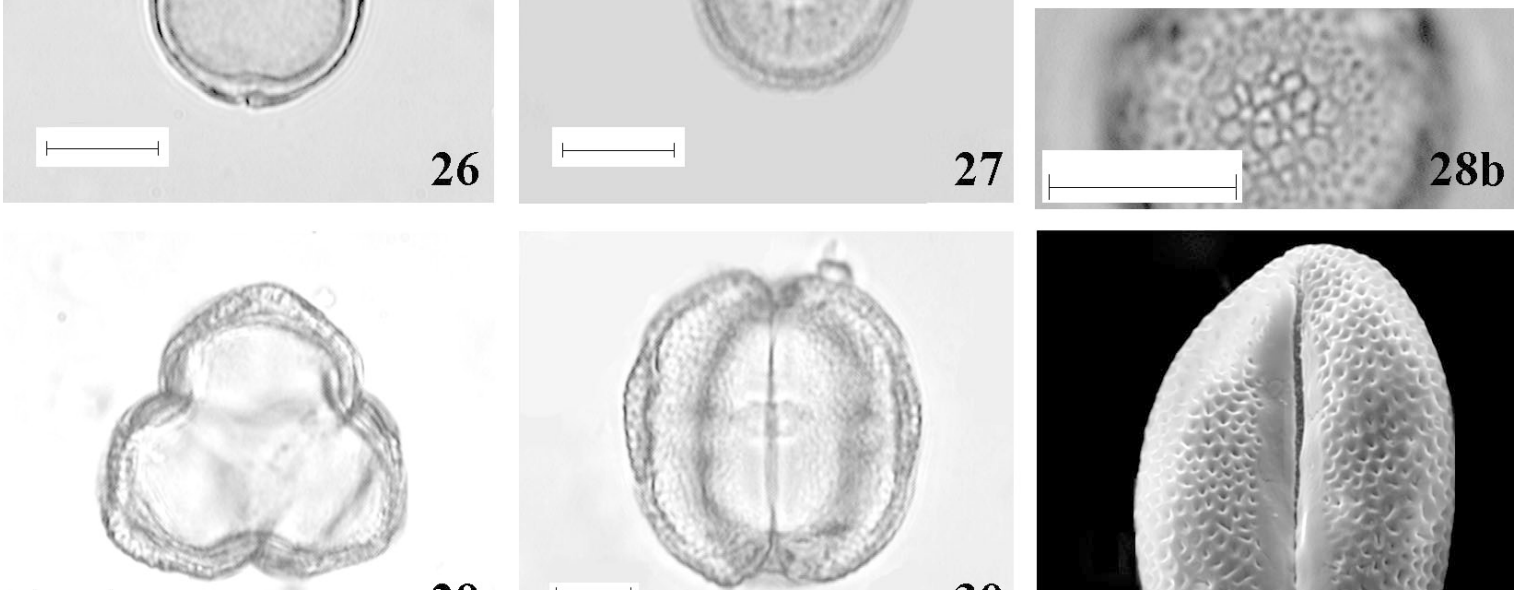

29

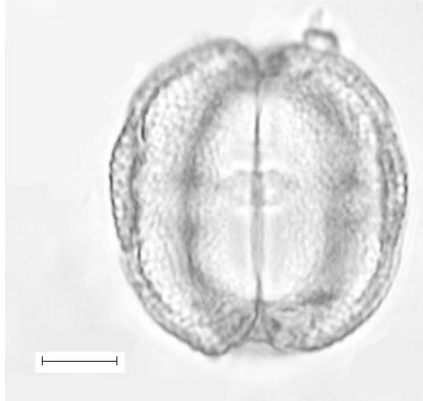

30
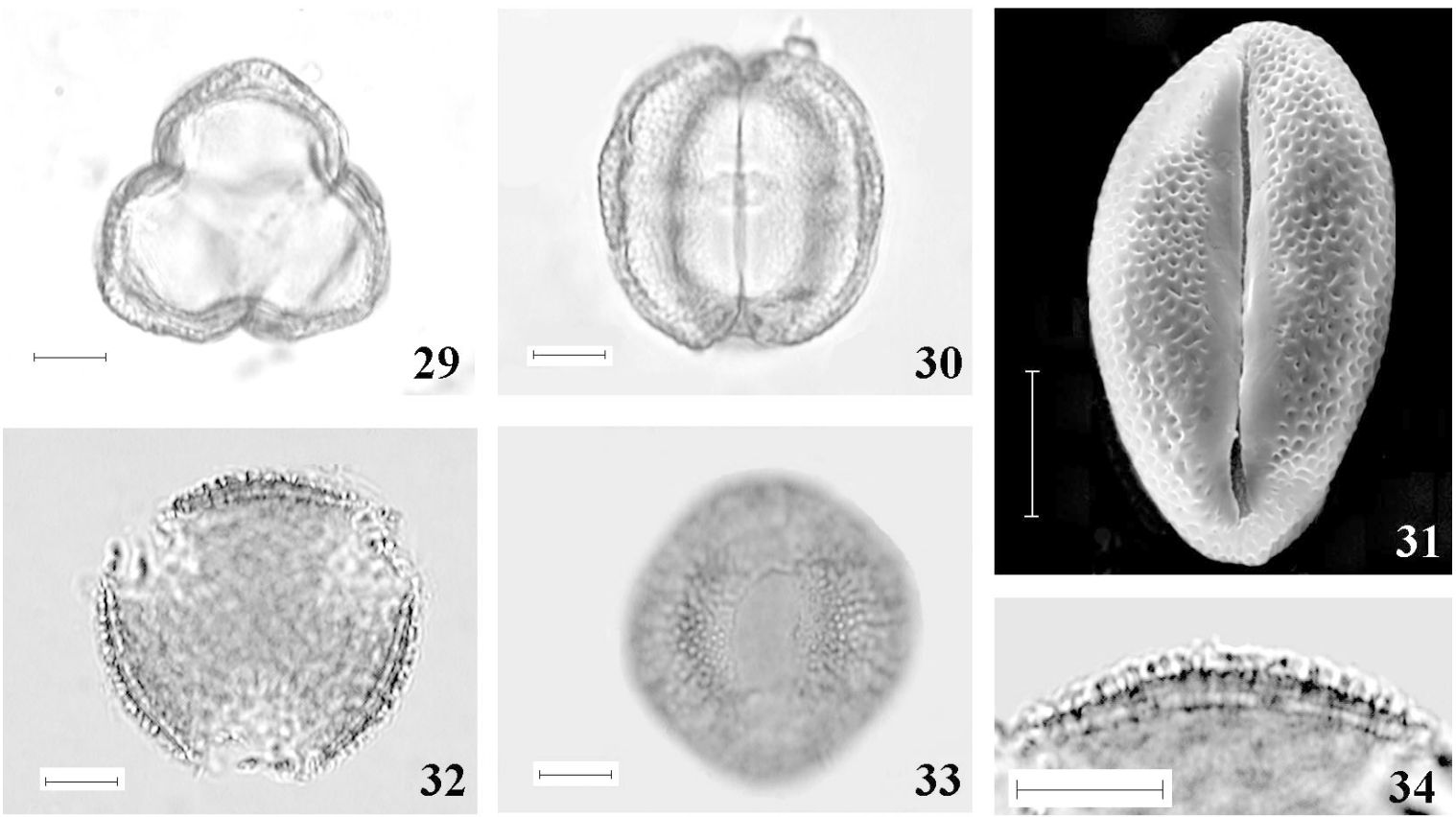

Figuras 24-34. Fotomicrografias e eletromicrografias dos grãos de pólen de Euphorbiaceae. 24-25. Pausandra morisiana (Casar.) Radlk. 24. Vista geral e contorno. 25. ML, em dois níveis de focalização. 26-28. Pera glabrata (Schott) Baill. 26. Contorno em vista polar. 27. Vista equatorial evidenciando a abertura. 28. ML, em dois níveis de focalização. 29-31. Sebastiania corniculata (Vahl.) Muell. Arg. 29. Vista polar, contorno. 30. Vista equatorial evidenciando a abertura. 31. Vista equatorial (MEV). $32-34$. Tetrorchidium rubrivenium Poepp. 32. Contorno em vista polar. 33. Vista equatorial evidenciando a abertura. 34. Corte óptico no pólo. Barras $=10 \mu \mathrm{m}$.

Figures 24-34. Light and scanning electron micrographs of pollen grains of Euphorbiaceae. 24-25. Pausandra morisiana (Casar.) Radlk. 24. General view and outline. 25. High and low focus L.O. 26-28. Pera glabrata (Schott) Baill. 26. Polar view, outline. 27. Equatorial view showing of aperture. 28. L.O. in high and low focus 29-31. Sebastiania corniculata (Vahl.) Muell. Arg. 29. Polar view, outline. 30. Equatorial view showing aperture. 31. Equatorial view (SEM). 32-34. Tetrorchidium rubrivenium Poepp. 32. Polar view, outline. 33. Equatorial view showing of aperture. 34. Optical section at polar view. Bars $=10 \mu \mathrm{m}$. 
Tabela 3. Medidas $(\mu \mathrm{m})$ dos grãos de pólen inaperturados de Euphorbiaceae $(n=25)$; exina e ornamentação $(n=10)$. $(\mathrm{FV}=$ faixa de variação; $\bar{x}=$ média aritmética; $s_{\overline{\times}}=$ desvio padrão da média; $s=$ desvio da amostra; $\mathrm{V}=$ coeficiente de variabilidade; $\mathrm{IC}=$ intervalo de confiança).

Table 3. Measures $(\mu \mathrm{m})$ of inaperturate pollen grains of Euphorbiaceae $(n=25)$; exine and ornamentation $(n=10)$. $(\mathrm{FV}=$ range; $\overline{\mathrm{x}}=$ arithmetic mean; $s_{\overline{\mathrm{x}}}=$ standard deviation of medium; $s=$ standard deviation of sample; $\mathrm{V}=$ coefficient of variability; $\mathrm{IC}=$ confidence interval).

\begin{tabular}{cccc}
\hline \multirow{2}{*}{ Grandezas } & & \multicolumn{2}{c}{ Espécies } \\
\cline { 3 - 4 } Diâmetro & & Croton macrobothrys & Pausandra morisiana \\
& $\mathrm{FV}$ & $51,8-61,6$ & $41,6-56,4$ \\
& $\bar{x} \pm s_{\bar{x}}$ & $56,4 \pm 0,6$ & $49,3 \pm 0,7$ \\
& $S$ & 3,0 & 3,4 \\
Ornamentação & $\mathrm{V} \%$ & 5,4 & 6,9 \\
exina & $\mathrm{IC}(95 \%)$ & $55,2-57,6$ & $47,9-50,7$ \\
sexina & Diâmetro da Unidade & 5,7 & 6,2 \\
nexina & Mediana da Subunidade & 1,8 & 2,9 \\
& $\bar{x}$ & 3,3 & 5,6 \\
& $\bar{x}$ & 2,4 & 4,3 \\
& $\bar{x}$ & 0,9 & 1,3 \\
\hline
\end{tabular}

largos, endoaberturas lolongadas de contorno irregular; exina com padrão-Croton, na qual as unidades de ornamentação têm, predominantemente, 4-5 subunidades de ornamentação, subunidades com ápices psilados, sexina simplescolumelada, nexina mais espessa que a sexina.

Família Lecythidaceae (figuras 36-38; tabelas 4-5).

Cariniana estrellensis (Raddi) O. Ktze. - Grãos de pólen médios; isopolares; âmbito circular; prolatos; 3-colporados, colpos longos com margem nítida, espessa, geralmente constritos, endoaberturas de difícil visualização; exina reticulado-rugulada, podendo-se observar alguns pilos isolados, sexina ligeiramente mais espessa que a nexina.

Família Malvaceae (figuras 39-44; tabelas 4-5).

Talipariti tiliaceum var. pernambucense (Arruda) Fryxell [= Hibiscus pernambucensis Arruda] (figuras 39-40) - Grãos de pólen muito grandes; esféricos; apolares; pantoporados, poros grandes, recobertos por sexina granulosa; exina espinhosa, espinhos cônicos, longos, situados sobre uma pequena elevação da sexina, ápice arredondado, base ligeiramente bulbosa, sexina baculada entre os espinhos, nexina mais espessa que a sexina na região entre os espinhos.

Sida rhombifolia L. (figuras 41-42) - Grãos de pólen grandes; esféricos; apolares; pantoporados, poros pequenos e escassos; exina espinhosa, com numerosos espinhos cônicos, curtos situados sobre elevações da sexina que tem forma de calota, ápice pontiagudo, base bulbosa, sexina com grânulos esparsos entre os espinhos, nexina mais espessa que a sexina na região entre os espinhos.

Urena lobata L. (figuras 43-44) - Grãos de pólen muito grandes; esféricos; apolares; pantoporados, com numerosos poros nítidos, com margem, recobertos por elementos de sexina; exina espinhosa, com dois tipos de espinhos num mesmo grão de pólen: um tipo cônico, longo, com ápice arredondado, e outro oblongo, curto, com ápice arredondado, ambos com base não bulbosa e situados sobre sexina não elevada, sexina granulada entre os espinhos, nexina mais espessa que a sexina.

Família Phytolaccaceae (figuras 45-51; tabela 4).

Petiveria alliacea L. (figuras 45-47) - Grãos de pólen médios, apolares, hexagonais; 12-pantocolpados, colpos com contorno irregular e de difícil visualização sob ML, distribuídos uniformemente pela superficie do grão de pólen, formando grupos de 3 colpos; exina esparsamente espiculada, sexina mais espessa que a nexina.

Phytolacca thyrsiflora Fenzl ex Schm. (figuras 48-51) - Grãos de pólen médios; isopolares; âmbito subtriangular; oblato-esferoidais; 3-colpados, colpos longos, com margem delgada; exina espiculadoperfurada na região polar e reticulada com espículos sobre os muros na região do mesocolpo, sexina mais espessa que a nexina. 

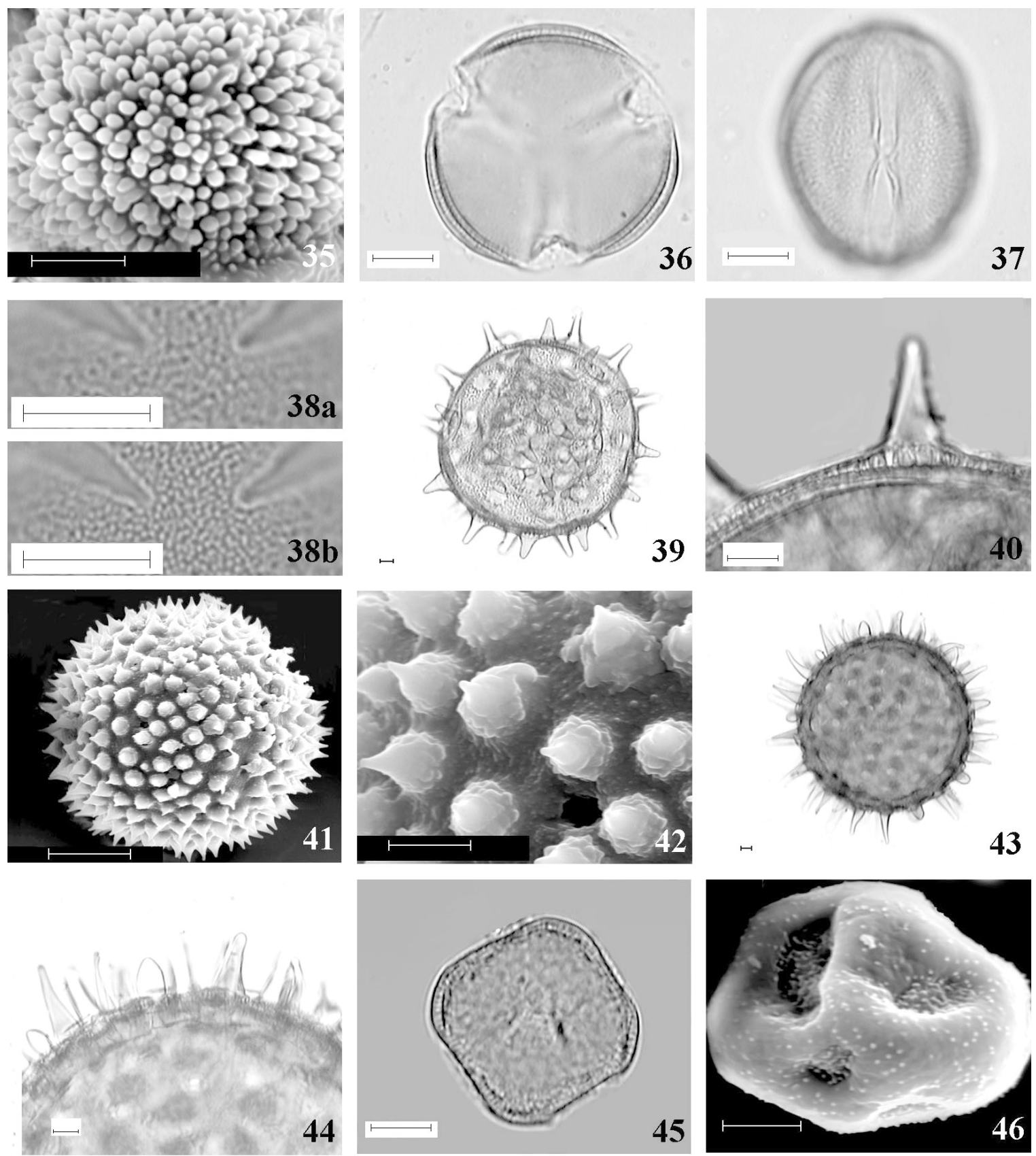

Figura 35-46. Fotomicrografias e eletromicrografias dos grãos de pólen de Euphorbiaceae (35), Lecythidaceae (36-38), Malvaceae (39-44) e Phytolaccaceae (45-46). 35. Tetrorchidium rubrivenium Poepp. - detalhe da ornamentação (MEV). 36-38. Cariniana estrellensis (Raddi) O. Ktze. 36. Vista polar em corte óptico. 37. Vista equatorial evidenciando a abertura. 38. ML, em dois níveis de focalização. 39-40. Talipariti tiliaceum var. pernambucense (Arruda) Fryxell. 39. Vista geral. 40. Corte óptico, mostrando o espinho. 41-42. Sida rhombifolia L. 41. Vista geral (MEV). 42. Detalhe da ornamentação (MEV). 43-44. Urena lobata L. 43. Contorno e vista geral. 44. Corte óptico, mostrando os espinhos. 45-46. Petiveria alliacea L. 45. Vista geral. 46. Vista geral, mostrando as aberturas (MEV). Barras $=2 \mu \mathrm{m}(35) ; 10 \mu \mathrm{m}(36-40,43-45) ; 20 \mu \mathrm{m}(41) ; 5 \mu \mathrm{m}(42,46)$.

Figure 35-46. Light and scanning electron micrographs of pollen grains of Euphorbiaceae (35), Lecythidaceae (36-38), Malvaceae (39-44) and Phytolaccaceae (45-46). 35. Tetrorchidium rubrivenium Poepp. - detail of ornamentation (SEM). 36-38. Cariniana estrellensis (Raddi) O. Ktze. 36. Polar view, optical section. 37. Equatorial view showing aperture. 38. L.O. in high and low focus. 39-40. Talipariti tiliaceum var. pernambucense (Arruda) Fryxell. 39. General view and outline. 40. Detail of spine in optical section. 41-42. Sida rhombifolia L. 41. General view (SEM). 42. Detail of ornamentation (SEM). 43-44. Urena lobata L. 43. General view, outline. 44. Detail of spine in optical section. 45-46. Petiveria alliacea L. 45. General view, outline. 46. General view showing apertures (SEM). Bars $=2 \mu \mathrm{m}(35) ; 10 \mu \mathrm{m}(36-40,43-45) ; 20 \mu \mathrm{m}(41) ; 5 \mu \mathrm{m}(42,46)$. 


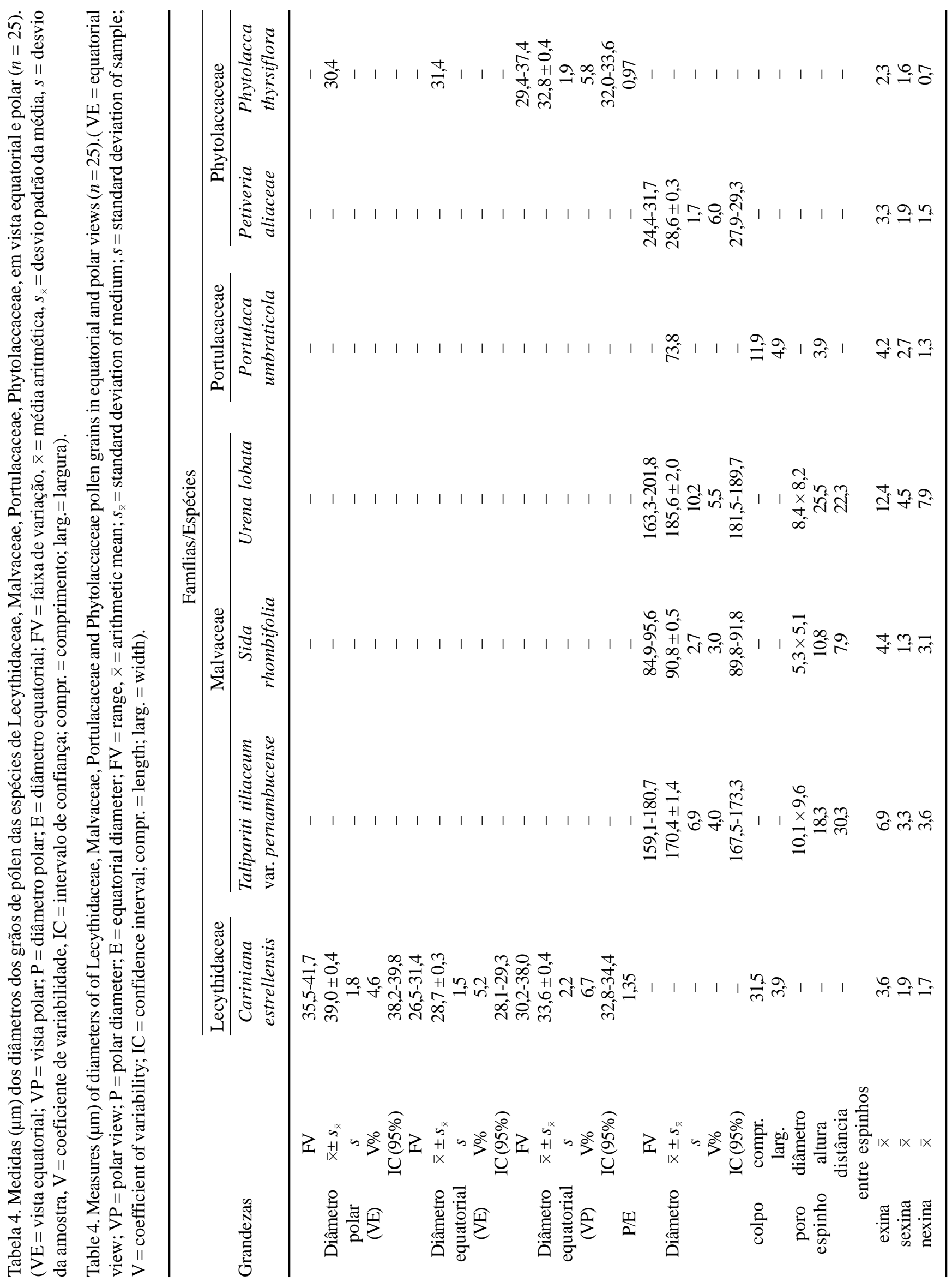


Família Portulacaceae (figuras 52-53; tabela 4).

Portulaca umbraticola H.B.K. (figuras 52-53) Grãos de pólen grandes; apolares; pantocolpados, colpos curtos, estreitos de contorno irregular, distribuidos uniformemente por toda a superfície do grão, formando áreas mais ou menos tetra ou pentagonais; exina espinhoso-perfurada, com numerosos espinhos cônicos e pontiagudos, de diferentes tamanhos, perfurações aneladas, tubuliformes, sexina mais espessa que a nexina.

\section{Discussão}

Aquifoliaceae - Barth \& Costa (1993) descreveram os grãos de pólen de Ilex amara (Vell.) Loes, I. dumosa Reissek e I. theezans Mart. ex Reissek, enquanto que Makino-Watanabe \& Jung-Mendaçolli (1994), além de estudarem os das duas últimas espécies, também descreveram os de I. integerrima (Vell.) Reissek. Os resultados obtidos no presente trabalho concordam com os apresentados pelos autores acima citados. Ferreira
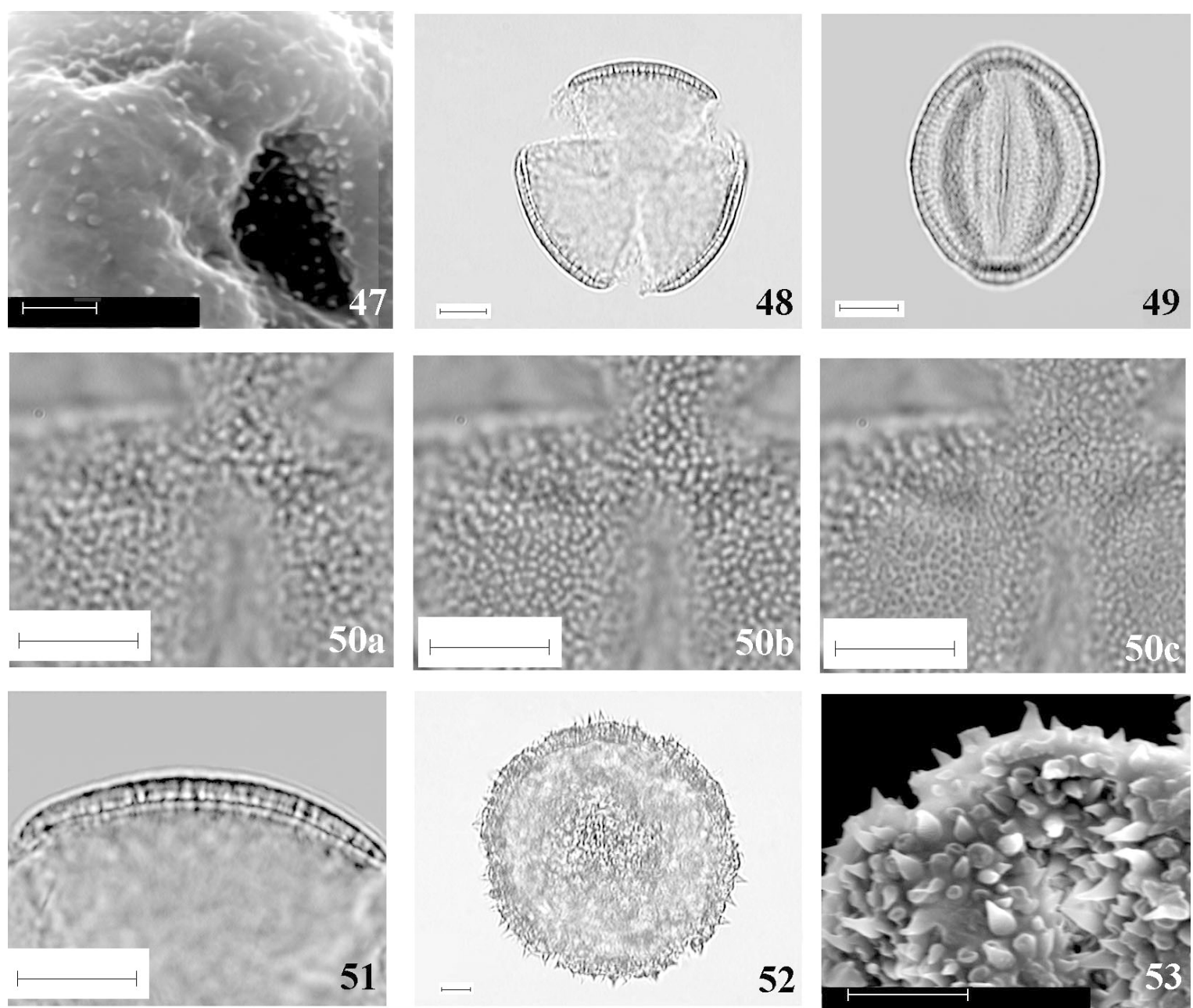

Figura 47-53. Fotomicrografias e eletromicrografias dos grãos de pólen de Phytolaccaceae (47-51) e Portulacaceae (52-53). 47. Petiveria alliacea L. Detalhe da ornamentação (MEV). 48-51. Phytolacca thyrsiflora Fenzl ex Schm. 48. Contorno em vista polar. 49. Vista equatorial evidenciando a abertura central. 50. ML, em tres níveis de focalização. 51. Corte óptico, em vista polar. 52-53. Portulaca umbraticola H.B.K. 52. Vista geral e contorno, evidenciando os espinhos. 53. Detalhe da ornamentação (MEV). Barras $=2 \mu \mathrm{m}(47) ; 10 \mu \mathrm{m}(48-53)$.

Figure 47-53. Light and scanning electron micrographs of pollen grains of Phytolaccaceae (47-51) and Portulacaceae (52-53). 47. Petiveria alliacea L. Detail of ornamentation (SEM). 48-51. Phytolacca thyrsiflora Fenzl ex Schm. 48. Polar view, outline. 49. Equatorial view, showing of aperture. 50. L.O. in high and low focus. 51. Optical section in polar view. 52-53. Portulaca umbraticola H.B.K. 52. General view and outline showing of spine. 53. Detail of ornamentation (SEM). Bars $=2 \mu \mathrm{m}(47) ; 10 \mu \mathrm{m}$ (48-53). 
Tabela 5. Medidas ( $\mu \mathrm{m}$ ) dos grãos de pólen dos materiais de comparação de Aquifoliaceae, Euphorbiaceae, Lecythidaceae e Malvaceae. $(n=10)$. ( $\mathrm{DE}=$ diâmetro equatorial; $\mathrm{VP}=$ vista polar; $\mathrm{DP}=$ diâmetro polar; $\mathrm{VE}=$ vista equatorial; Diâm. = diâmetro).

Table 5. Measure $(\mu \mathrm{m})$ of pollen grains of comparison specimens of Aquifoliaceae, Euphorbiaceae, Lecythidaceae and Malvaceae. $(n=10)$. ( $\mathrm{DE}=$ equatorial diameter; $\mathrm{VP}=$ polar view; $\mathrm{DP}=$ polar diameter; $\mathrm{VE}=$ equatorial view; Diâm. $=$ diameter $)$.

\begin{tabular}{|c|c|c|c|c|c|}
\hline Famílias/Espécies & Coletor e n. de herbário & $\begin{array}{c}\mathrm{DE} \\
(\mathrm{VP})\end{array}$ & $\begin{array}{c}\text { DP } \\
(\mathrm{VE})\end{array}$ & $\begin{array}{c}\mathrm{DE} \\
(\mathrm{VE})\end{array}$ & Diâm. \\
\hline \multicolumn{6}{|l|}{ AQUIFOLIACEAE } \\
\hline \multirow[t]{2}{*}{ Ilex dumosa } & R. D. Marassi et al. 51 & 26,6 & 30,3 & 29,4 & - \\
\hline & M. Sugiyama 987 & 27,2 & 27,5 & 28,0 & - \\
\hline I. theezans var. acrodonta & M. Sugiyama 978 & 29,7 & 28,9 & 27,6 & - \\
\hline \multirow[t]{3}{*}{ I. theezans var. grandifolia } & F. Barros, 2322 & 35,6 & 37,2 & 36,1 & - \\
\hline & D.A. De Grande \& E.A. Lopes 3 & 33,8 & 34,4 & 35,5 & - \\
\hline & M. Kirizawa 1527 & 34,5 & 36,1 & 35,2 & - \\
\hline \multicolumn{6}{|l|}{ EUPHORBIACEAE } \\
\hline \multirow[t]{2}{*}{ Alchornea triplinervea } & E. Forero et al. 8673 & 20,9 & 18,1 & 21,0 & - \\
\hline & F. Barros 1974 & 26,3 & 26,9 & 29,9 & - \\
\hline Croton macrobothrys & R.D. Xavier et al. 16 & - & - & - & 58,1 \\
\hline \multirow[t]{5}{*}{ Dalechampia ficifolia } & I. Cordeiro et al. 350 & - & 56,5 & 49,2 & - \\
\hline & F. Barros 469 & 37,8 & 51,8 & 48,9 & - \\
\hline & I. C.C. Macedo et al. 80 & 47,5 & 58,1 & 52,8 & - \\
\hline & E. Forero et al. 8615 & 44,7 & 54,4 & 47,5 & - \\
\hline & D. A. De Grande \& E.A. Lopes 350 & 37,6 & 43,1 & 39,6 & - \\
\hline \multirow[t]{2}{*}{ Euphorbia insulana } & I. Cordeiro et al. 499 & 37,7 & 37,4 & 36,4 & - \\
\hline & T.M. Cerati \& S.A. Chiea 347 & 40,1 & 39,3 & 39,6 & - \\
\hline \multirow[t]{3}{*}{ Pera glabrata } & F. Barros 1499 & 17,9 & 18,3 & 17,4 & - \\
\hline & M. Kirizawa 1975 & 16,2 & 17,5 & 16,9 & - \\
\hline & D.A. De Grande \& E.A. Lopes 215 & 17,2 & 18,6 & 17,3 & - \\
\hline \multirow[t]{2}{*}{ Sebastiania corniculata } & E. Forero et al. 8630 & 42,6 & 41,9 & 37,7 & - \\
\hline & M.R.O. Santos et al. 6 & 38,9 & 40,8 & 38,1 & - \\
\hline \multicolumn{6}{|l|}{ LECYTHIDACEAE } \\
\hline \multirow[t]{2}{*}{ Cariniana estrellensis } & S.L. Jung-Mendaçolli \& E.A. Lopes 550 & 29,2 & 37,7 & 30,0 & - \\
\hline & F. Barros \& P. Martuscelli 1635 & 30,2 & 39,1 & 31,2 & - \\
\hline \multicolumn{6}{|l|}{ MALVACEAE } \\
\hline \multirow{3}{*}{$\begin{array}{l}\text { Talipariti tiliaceum } \\
\text { var. pernambucense }\end{array}$} & O. Yano s.n. (SP154662) & - & - & - & 156,1 \\
\hline & A. Custodio Filho 497 & & & & 156,5 \\
\hline & A.M. Fortes et al. 9 & - & - & - & 162,4 \\
\hline Sida rhombifolia & C.F.S. Muniz \& A.C. Filho 54 & - & - & - & 81,0 \\
\hline Urena lobata & M. Góes 13 & - & - & - & 172,1 \\
\hline
\end{tabular}

\& Salgado-Labouriau (1966), analisando os grãos de pólen de I. asperula Mart. var. martinsiana Loes. e I. conocarpa Reissek, descreram-nos como 3-colpados divergindo das espécies aqui estudadas, cujos grãos de pólen mostraram-se 3-colporados.

Groppo \& Pirani (2002), salientaram que Ilex amara é freqüentemente citada como I. dumosa, mas a delimitação desses táxons não é clara, necessitando de estudos mais aprofundados; entretanto, os autores, preferiram adotar o binômio Ilex amara, o qual, deverá ter prioridade em caso de sinonimização desses táxons.
Os mesmos autores ressaltaram que alguns espécimes de I. theezans são freqüentemente identificados como I. integerrima Reissek, por ser difícil a distinção entre os dois táxons, e por isso adotaram o binômio mais amplamente utilizado na literatura (I. theezans). Neste trabalho, foram mantidos os epítetos I. dumosa, I. integerrima e I. theezans, apesar das considerações apresentadas por Groppo \& Pirani (2002). Através dos dados polínicos obtidos no presente estudo, não foi possível a distinção destes táxons, pois os seus grãos de pólen, apresentam características morfológicas muito 
semelhantes entre si, mostrando apenas pequenas variações quanto ao tamanho, característica também observada por Lobreau-Callen (1975) que estudou várias espécies de Ilex L. A autora correlacionou diferenças nas dimensões dos grãos de pólen, com a origem geográfica (latitude, longitude, altitude, clima) das espécies, concluindo que os grãos de pólen de uma mesma espécie variam quanto ao tamanho dependendo da origem geográfica em que a mesma ocorre.

Euphorbiaceae - Os grãos de pólen de Actinostemon concolor (Spreng.) Muell. Arg. foram descritos por Punt (1962), cujos resultados são semelhantes aos aqui encontrados, quanto ao tamanho dos grãos de pólen e ao tipo de abertura, embora aquele autor não tenha observado a presença de opérculo, característica bem nítida no espécime aqui estudado. Quanto à ornamentação da exina, Punt (1962) a descreveu como psilada, ao passo que, no presente estudo, observou-se que esta é microrreticulada.

Os grãos de pólen de Alchornea triplinervia (Spreng.) Muell. Arg. foram analisados por Punt (1962) e Salgado-Labouriau (1967), enquanto os de Aparisthmium cordatum (A. Juss.) Baill. foram estudados por Punt (1962). Os resultados apresentados por Punt (1962) indicam que essas duas espécies apresentam grãos de pólen muito semelhantes, tendo sido inseridos, por esse autor, em um mesmo mesmo tipo polínico. Essas observações também foram confirmadas no presente estudo, diferindo de Punt (1962) e Salgado-Labouriau (1967), apenas com relação à ornamentação da sexina que foi considerada por aqueles autores como psilada, enquanto no presente estudo evidenciou-se que esta é rugulada quando observada sob MEV.

Até o presente momento não foram encontrados dados na literatura para Croton macrobothrys Baill., entretanto alguns autores estudaram outras espécies do gênero sob ML e MEV. Estudos realizados em microscopia de luz, confirmam que os grãos de pólen de Croton L. apresentam ornamentação do tipo padrãoCroton, com subunidades clavadas psiladas ou clavadas pontiagudas (Punt 1962); em número de 5-7 subunidades, posicionadas sobre uma área circular (Salgado-Labouriau 1967) ou, ainda, com subunidades clavadas de forma circular a triangular (Roubick \& Moreno 1991). Oliveira \& Santos (2000) mencionaram, apenas, que as unidades estruturais (subunidades) podem ter formato homogêneo ou heterogêneo. Thanikaimoni et al. (1984), ao estudarem três espécies de Croton (C. angustatus Urban, C. erythroxyloides Muell. Arg. e $C$. matourensis Aubl.) sob ML e MEV, consideraram que as duas primeiras apresentam padrão crotonóide, e a terceira, padrão crotonóide não muito evidente, uma vez que apresentou retículos com muros bem desenvolvidos. Carreira et al. (1996) observaram sob MEV seis espécies de Croton, verificando variação na forma e ornamentação das subunidades do padrãoCroton: subunidades com clavas aproximadamente elípticas, estriadas com espículo apical; subunidades com clavas subtriangulares e estriadas; subunidades com clavas arredondadas, psiladas ou estriadas sem espículo apical; ou, mais raramente, subunidades com um padrão reticulado com clavas mais ou menos elípticas, espinhosas, estriadas, posicionadas sobre as junções dos muros dos retículos e numerosas clavas menores dentro dos lumens. Nowicke (1994), estudando 13 espécies de Croton sob $\mathrm{MEV}$, verificou a grande variação no tamanho, distribuição e ornamentação das subunidades do padrão-Croton. No presente estudo Croton macrobothrys, observado sob ML e MEV, apresentou grãos de pólen com padrão-Croton, com 6-7 subunidades psiladas e poucos grânulos dentro dos lumens.

Não foram encontrados na literatura dados palinológicos para Dalechampia filicifolia Lam., porém outras espécies do gênero foram descritas por alguns autores, destacando-se entre eles Punt (1962), Khan (1968), Roubick \& Moreno (1991) e Nowicke (1994). As observações palinológicas para as espécies de Dalechampia L., apresentadas pelos referidos autores, de um modo geral, são muito semelhantes, demonstrando ser um gênero estenopolínico, havendo diferenças somente no tamanho dos grãos de pólen.

As espécies do gênero Euphorbia L. foram bastante estudadas do ponto de vista palinológico por vários autores (Punt 1962, Salgado-Labouriau 1967, Khan 1968, El-Ghazaly 1989, El-Ghazaly \& Chaudhary 1993, Chaudhary \& El-Ghazaly 1994, Nowicke 1994, Park 1998, Carneiro-Torres et al. 2002). Para esses autores, os grãos de pólen das espécies de Euphorbia são pequenos a médios, isopolares, raramente heteropolares, circulares a triangulares, planoaperturados a lobados, oblato-esferoidais, prolatoesferoidais, subprolatos a prolatos, 3-colporados, raramente policolporados, com colpos longos, estreitos a largos, com margem larga, com ou sem opérculo, endoabertura circular, lalongada a lolongada, às vezes com costa, exina psilada, granulada, rugulada, foveolada, perfurada, microrreticulada, reticulada a espinhosa. No presente estudo Euphorbia insulana Vell. enquadrou-se dentro dessas descrições, apresentando grãos de pólen 3-colporados, colpos longos e estreitos, com margem, endoabertura lolongada e sexina reticulada. 
Punt (1962) descreveu os grãos de pólen de Pausandra morisiana (Casar.) Radlk. com resultados semelhantes aos do presente estudo, exceto com relação ao tamanho dos mesmos que, segundo o referido autor, é maior que os aqui estudados.

Os grãos de pólen de Pera glabrata (Schott) Baill. foram estudados por Punt (1962) e Nowicke et al. (1998). De acordo com Punt (1962), os grãos de pólen desta espécie apresentam exina psilada, enquanto no presente estudo, observou-se que ela é reticulada. Nowicke et al. (1998) analisaram dois espécimes de P. glabrata ocorrentes na Venezuela e no Brasil e seus resultados mostram grãos de pólen menores no espécime coletado no Brasil. Os dados referentes ao espécime brasileiro mostram grãos de pólen aproximadamente do mesmo tamanho que os analisados no presente trabalho. Com relação à ornamentação da exina, Nowicke et al. (1998) relatam a presença de teto punctado, com fibras finas não organizadas e pequenas saliências arredondadas.

Os grãos de pólen de Sebastiania corniculata (Vahl.) Muell. Arg. foram descritos por Punt (1962) e Salgado-Labouriau (1967). Com relação às aberturas somente Punt (1962) observou a presença de costa no colpo e nas endoaberturas. Quanto à ornamentação da sexina houve discordância entre os resultados daqueles autores e os do presente estudo, sendo que para Punt (1962), a espécie apresenta sexina psilada, enquanto que para Salgado-Labouriau (1967) ela é pilada, no presente estudo as observações sob ML e MEV evidenciaram que a sexina é microrreticulada.

Tethrorchidium rubrivenium Poepp. foi examinada palinologicamente por Punt (1962), Nowicke (1994) e Loubreau-Callen \& Cervera (1997). Houve divergência quanto ao tipo de abertura, pois somente Punt (1962) encontrou grãos de pólen 3-colpados, enquanto que os demais autores consideraram a espécie como tendo grãos de pólen 3-colporados, o que está de acordo com o presente trabalho. Quanto à ornamentação da sexina, Nowicke (1994) e Loubreau-Callen \& Cervera (1997) descreveram-na como tendo subunidades estriadas, divergindo de Punt (1962) que citou subunidades baculado-verrucadas. Deve-se ressaltar que Punt (1962) não utilizou MEV nos seus estudos, ao contrário dos autores acima citados. No presente estudo, a espécie observada sob ML e MEV apresentou subunidades psiladas.

Lecythidaceae - Cariniana estrellensis (Raddi) O. Ktze, a única espécie desta família aqui estudada, apresentou grãos de pólen 3-colporados, conforme foi também observado por Jung-Mendaçolli et al. (1987). Entretanto, Barth \& Silva (1965) mencionam a ocorrência de grãos de pólen 3-colpados para essa espécie, provavelmente devido à difícil visualização da endoabertura. A presença desta abertura pôde ser comprovada, no presente estudo, analisando-se detalhadamente as vistas polar e equatorial. Os dados aqui obtidos mostraram, ainda, exina com ornamentação reticulado-rugulada, sendo esta observação contrária à de Barth \& Silva (1965) e de Jung-Mendaçolli et al. (1987), que mencionaram exina granulada.

Malvaceae - Os dados aqui obtidos para Sida rhombifolia L. mostram grãos de pólen esféricos, pantoporados e espinhosos, confirmando os resultados de Barth (1975), Martínez (1982), Roubik \& Moreno (1991) e Jiménez-Reyes (2003).

Talipariti tiliaceum var. pernambucense (Arruda) Fryxell foi estudada taxonomicamente, na Ilha do Cardoso, por Chiea \& Silva (1992) sob o nome de Hibiscus pernambucensis Arruda. Posteriormente, a mesma foi sinonimizada por Fryxell (2001), como Talipariti tiliaceum var. pernambucense (Arruda) Fryxell, epíteto adotado no presente estudo.

Os grãos de pólen da espécie, acima citada, foram estudados por Silva (1966) e Silva et al. (2004), sob o nome de Hibiscus tiliaceus L. e H. pernambucensis, por Erdtman (1952), Rao \& Lee (1970), Huang (1972) e Christensen (1986) sob Hibiscus tiliaceus, por Barth (1975) sob Hibiscus tiliaceus var. pernambucensis. Seus grãos de pólen foram descritos por Erdtman (1952), Silva (1966) e Huang (1972), como esféricos, pantoporados, sexina tectado-baculada, com superfície ornada por espinhos e grânulos; essas características também foram registradas no presente trabalho. Segundo Barth (1975), a espécie apresenta sexina ondulada e perfurada por pontos distintos, enquanto para Rao \& Lee (1970) ela é reticulada entre os poros, características aqui confirmadas. Christensen (1986) ressaltou, em $H$. tiliaceus, a presença de opérculos nos poros, bem como a ocorrência de dois tipos de pólen: um com espinhos longos, delgados e cônicos e outro, mais raro, com espinhos curtos, pontiagudos e freqüentemente distorcidos, estas características não foram observadas no presente estudo. Silva et al. (2004), estudaram os grãos de pólen de Hibiscus tiliaceus e H. pernambucensis separadamente, encontrando caracteristicas morfopolínicas diferentes as quais possibilitaram a separação das duas espécies. Com relação ao tamanho os grãos de pólen descritos por Silva et al. (2004) são significativamente menores que os aqui estudados. 
Os grãos pólen de Urena lobata L. foram estudados por Rao \& Lee (1970), Huang (1972) e Christensen (1986). As descrições gerais apresentadas por esses autores concordam com os dados aqui obtidos, discordando apenas, dos de Rao \& Lee (1970), quanto à ornamentação da exina, que segundo estes autores é reticulada.

A sexina espinhosa do pólen das Malvaceae, segundo Oliveira \& Santos (2002), é um caráter importante para a taxonomia da família; nas espécies aqui estudadas observou-se a presença de espinhos os quais podem estar situados sobre uma elevação da sexina (Talipariti tiliaceum var. pernambucense, Sida rhombifolia) ou não (Urena lobata). Urena lobata destaca-se das demais espécies pela presença de dois tipos de espinhos (cônicos e oblongos) e pela base destes não bulbosa; já S. rhombifolia difere dos demais táxons, por apresentar espinhos com ápice pontiagudo.

Phytolaccaceae - Quando os dados aqui apresentados para Petiveria alliacea $\mathrm{L}$. foram confrontados com os de outros autores que também estudaram palinologicamente a espécie (Nowicke 1968, 1975, Barth \& Barbosa 1972, Bortenschlager 1973, Roubik \& Moreno 1991), verificou-se uma concordância em relação ao tipo de abertura (12-colpados), com exceção de Barth \& Barbosa (1972) que definiram os grãos de pólen como 12-porados. Entretanto constatou-se uma divergência em relação à exina, que foi descrita como reticulado-granulada (Barth \& Barbosa 1972), reticulada (Nowicke 1968), baculada (Roubick \& Moreno 1991) e espiculada (Bortenschlager 1973). No presente estudo, a ornamentação da exina foi definida como esparsamente espiculada. Os resultados palinológicos encontrados na literatura evidenciaram um consenso geral entre os diversos autores (Nowicke 1968, Barth \& Barbosa 1972, Bortenschlager 1973, Silvestre \& Carreira 1985), quanto à caracterização morfológica dos grãos de pólen de Phytolacca thyrsiflora Fenzl ex Schm., que os descreveram como 3-colpados com sexina espiculado-perfurada, exceto Nowicke (1968) que se refere à sexina como sendo reticulada. As observações feitas por esses autores são muito semelhantes àquelas do presente estudo, com uma ressalva somente para os grãos de pólen aqui observados que, em vista equatorial, mostraram sexina reticulada, com espículos sobre os muros.

Portulacaceae - Embora não tenham sido encontrados dados palinológicos na literatura para Portulaca umbraticola H.B.K., outras espécies do gênero foram estudadas por vários autores, tais como Erdtman (1952), Nowicke (1975), Roubick \& Moreno (1991), Nyananyo
(1992) e Silvestre-Capelato \& Corrêa (1995). Os dados apresentados por esses autores são semelhantes aos aqui observados, podendo o gênero Portulaca ser considerado estenopolínico.

Agradecimentos - À Dra. Maria Stella Fernandes SilvestreCapelato pela colaboração neste trabalho.

\section{Referências bibliográficas}

BARTH, O.M. 1975. Catálogo sistemático dos pólens das plantas arbóreas do Brasil Meridional. XVIII Malvaceae. Memórias do Instituto Oswaldo Cruz 73:1-18.

BARTH, O.M. \& BARBOSA, A.F. 1972. Catálogo sistemático dos pólens das plantas arbóreas do Brasil Meridional XIV - Nyctaginaceae e Phytolaccaceae. Memórias do Instituto Oswaldo Cruz 70:241-259.

BARTH, O.M. \& COSTA, K.M.R. 1993. Catálogo sistemático dos pólens das plantas arbóreas do Brasil Meridional. XXVI- Aquifoliaceae. Revista Brasileira de Biologia 53:305-309.

BARTH, O.M. \& MELHEM, T.S. 1988. Glossário ilustrado de palinologia. Editora da Universidade Estadual de Campinas, Campinas.

BARTH, O.M. \& SILVA, S.A.F. 1965. Catálogo sistemático dos pólens das plantas arbóreas do Brasil Meridional. VII. Thymelaeaceae, Lythraceae, Lecythidaceae, Rhizophoraceae e Combretaceae. Memórias do Instituto Oswaldo Cruz 63:255-278.

BARROS, F. 1992. Lecythidadecae. In Flora Fanerogâmica da Ilha do Cardoso (M.M.R.F. Melo, F. Barros, M.G.L. Wanderley, M. Kirizawa, S.L. Jung-Mendaçolli, \& S.A.C. Chiea, eds.). Instituto de Botânica, São Paulo v.2, p.27-30.

BARROS, F., MELO, M.M.R.F., CHIEA, S.A.C., KIRIZAWA, M., WANDERLEY, M.GL. \& JUNG-MENDAÇOLLI, S.L. 1991. Caracterização geral da vegetação e listagem das espécies ocorrentes. In Flora Fanerogâmica da Ilha do Cardoso (M.M.R.F. Melo, F. Barros, M.G.L. Wanderley, M. Kirizawa, S.L. Jung-Mendaçolli, \& S.A.C. Chiea, eds.). Instituto de Botânica, São Paulo v.1, p.1-184.

BORTENSCHLAGER, S. 1973. Morphologie pollinique des Phytolaccaceae. Pollen et Spores 15:227-253.

CARNEIRO-TORRES, D.S., SANTOS, F.A.R. \& GIULIETTI, A.M. 2002. A tribo Euphorbieae Dumort (Euphorbiaceae) na chapada Diamantina, Bahia, Brasil: Palinologia e implicações taxonômicas. Polibotánica 13:83-96.

CARREIRA, L.M.M., SECCO, R.S. \& BARTH, O.M. 1996. Pollen morphology of the lianescent species of the genus Croton (Euphorbiaceae). Grana 35:74-78.

CHAUdHARY, R. \& EL-GHAZALY, G. 1994. Pollen morphology of Euphobia caputmedusae. Grana 33:124-127. 
CHIEA, S.A.C. \& ROMANIUC NETO, S. 1992. Aquifoliaceae. In Flora Fanerogâmica da Ilha do Cardoso (M.M.R.F. Melo, F. Barros, M.G.L. Wanderley, M. Kirizawa, S.L. Jung-Mendaçolli \& S.A.C. Chiea, eds.). Instituto de Botânica, São Paulo v.2, p.15-20.

CHIEA, S.A.C. \& SILVA, T.R.S. 1992. Malvaceae. In Flora Fanerogâmica da Ilha do Cardoso (M.M.R.F. Melo, F. Barros, M.G.L. Wanderley, M. Kirizawa, S.L. JungMendaçolli \& S.A.C. Chiea, eds.). Instituto de Botânica, São Paulo v.2, p.9-13.

CHRISTENSEN, P.B. 1986. Pollen morphological studies in the Malvaceae. Grana 25:95-117.

CORDEIRO, I. 1992. Euphorbiaceae. In Flora Fanerogâmica da Ilha do Cardoso (M.M.R.F. Melo, F. Barros, M.G.L. Wanderley, M. Kirizawa, S.L. Jung-Mendaçolli \& S.A.C. Chiea, eds.). Instituto de Botânica, São Paulo v.3, p.11-165.

DE GRANDE, D.A. \& LOPES, E.A. 1981. Plantas da Restinga da Ilha do Cardoso (São Paulo, Brasil). Hoehnea 9:1-22.

EL-GHAZALY, G.A. 1989. Pollen and orbicule morphology of some Euphorbia species. Grana 28:243-259.

EL-GHAZALY, G.A. \& CHAUDHARY, R. 1993. Pollen morphology of some species of genus Euphorbia L. Review of Palaeobotany and Palynology 78:293-319.

ERDTMAN, G. 1952. Pollen morphology and plant taxonomyAngiosperms. Almqvist \& Wiksell, Stockholm.

ERDTMAN, G. 1960. The acetolysis method. A revised description. Svensk Botanisk Tidskrift 54:561-564.

FERREIRA, A.G. \& SALGADO-LABOURIAU, M.L. 1966. Pollen grains of plants of the "Cerrado". XV Aquifoliaceae, Flacourtiaceae and Meliaceae. Boletim do Museu Paraense Emílio Goeldi 24:1-11.

FRYXELL, P.A. 2001. Talipariti (Malvaceae), a segregate from Hibiscus. Contributions from the University of Michigan Herbarium 23:225-270.

FUNARI, F.L., STRUFFALDI-DE-VUONO, Y. \& SALUM, S.T. 1987. Balanço hídrico de duas áreas de Mata Atlântica: Reserva Biológica de Paranapiacaba e Parque Estadual da Ilha do Cardoso (Estado de São Paulo). In Anais do $6^{\circ}$ Congresso da Sociedade de Botânica de São Paulo, (M.F.A. Pereira \& M.A.S. Massei, eds.). Sociedade Botânica de São Paulo, Campinas, p.95-101.

FURLAN, A. 1992a. Portulacaceae. In Flora Fanerogâmica da Ilha do Cardoso (M.M.R.F. Melo., F. Barros, M.G.L. Wanderley, M. Kirizawa, S.L. Jung-Mendaçolli \& S.A.C. Chiea, eds.) Instituto de Botânica, São Paulo, v.2, p.21-22.

FURLAN, A. 1992b. Phytolaccaceae. In Flora Fanerogâmica da Ilha do Cardoso (M.M.R.F. Melo, F. Barros, M.G.L. Wanderley, M. Kirizawa, S.L. Jung-Mendaçolli \& S.A.C. Chiea, eds.) Instituto de Botânica, São Paulo v.2, p.23-26.

GROPPO, M. \& PIRANI, J.R. 2002. Aquifoliaceae. In Flora Fanerogâmica do Estado de São Paulo (M.G.L. Wanderley, G.J. Shepherd, A.M. Giulietti, T.S. Melhem, V. Bittrich. \& C. Kameyama, eds.). Instituto de Botânica, São Paulo v.2, p.31-37.
HUANG, T.C. 1972. Pollen flora of Taiwan. National Taiwan University, Botany Department Press, Taiwan.

JIMÉNEZ-REYES, M.N. 2003. Morfología de los granos de polen de la familia Malvaceae de Jalisco, México. V. Periptera, Phymosia, Robinsonella, Sida, Sphaeralcea y Wissadula. Ibugana 11:3-30.

JUNG-MENDAÇOLLI, S.L., MELHEM, T.S. \& BISSA, W.M. 1987. Flora Polínica da Reserva do Parque Estadual das Fontes do Ipiranga (São Paulo, Brasil). Famílias: 48Lecythiceae, 53-Turneraceae e 78-Saxifragaceae. Hoehnea 14:11-14.

KHAN, H.A. 1968. Contributions to the pollen morphology of the Euphorbiaceae. Journal of Palynology 4:21-35.

LOBREAU-CALLEN, D. 1975. Les variations dimensionnelles du pollen du genre Ilex (Aquifoliaceae) et leurs rapports avec le climat. Bulletin de La Société Botanique de France 122:179-199.

LOBREAU-CALLEN, D. \& CERVERA, M.S. 1997. Le pollen des Crotonoideae Apétales (Euphorbiaceae): Ultrastructure de l'exine. Review of Palaeobotany and Palynology 98:257-291.

MAKINO-WATANABE, H.M. \& JUNG-MENDAÇOLLI, S.L. 1994. Flora Polínica da Reserva do Parque Estadual das Fontes do Ipiranga (São Paulo, Brasil). Famílias: 103-Aquifoliaceae e 132-Loganiaceae. Hoehnea 21:39-45.

MARTÍNEZ, F.S. 1982. Morfologia polinica de algunas malvaceas mexicanas. Instituto Nacional de Antropologia e Historia. Coleccion Cientifica 127:1-88.

MELHEM,T.S. \& MATOS, M.E.R. 1972. Variabilidade de forma nos grãos de pólen de Eriope crassipes Benth. Labiatae. Hoehnea 2:1-10.

NEGREIROS, O.C., CARVALHO, C.T., CESAR, S.F., DUARTE, F.R., DESLER, W.O. \& THELEN, K.D. 1974. Plano de Manejo para o Parque Estadual da Ilha do Cardoso. Boletim Técnico do Instituto Florestal 9:1-56.

NOFFS, M.S. \& BATISTA-NOFFS, L.J. 1982a. Mapa da vegetação do Parque Estadual da Ilha do Cardoso evolução da vegetação secundária. Silvicultura em São Paulo 16:613-619.

NOFFS, M.S. \& BATISTA-NOFFS, L.J. 1982b. Mapa da vegetação do Parque Estadual da Ilha do Cardoso - as principais formações. Silvicultura em São Paulo 16:620-628.

NOWICKE, J.W. 1968. Palynotaxonomic study of the Phytolaccaceae. Annals of the Missouri Botanical Garden 55:294-364.

NOWICKE, J.W. 1975. Pollen morphology in the order Centrospermae. Grana 15:51-77.

NOWICKE, J.W. 1994. A palynological study of Crotonoideae (Euphorbiaceae). Annals of the Missouri Botanical Garden 81:245-269.

NOWICKE, J.W., TAKAHASHI, M. \& WEBSTER, G.L. 1998. Pollen morphology, exine structure and systematics of Acalyphoideae (Euphorbiaceae). Rewiew of Palaeobotany and Palynology 102:115-152. 
NYANANYO, B.L. 1992. Pollen morphology in the Portulacaceae (Centrospermae). Folia Geobotanica \& Phytotaxonomica 27:387-400.

OLIVEIRA, P.P. \& SANTOS, F.A.R. 2000. Morfologia polínica do gênero Croton L. (Euphorbiaceae) dos inselbergs da região de Milagres (Bahia-Brasil). Revista Universidade Guarulhos, Geociências 5:212-215.

OLIVEIRA, P.P. \& SANTOS, F.A.R. 2002. Flora polínica dos inselbergs da região de Milagres (BA, Brasil): Malvaceae. Acta Biologica Leopoldensia 24:25-35.

PARK, K. 1998. Monograph of Euphorbia sect. Tithymalopsis (Euphorbiaceae). Edinburgh Journal of Botany 55:161-208.

PUNT, W. 1962. Pollen morphology of the Euphorbiaceaae with special reference to taxonomy. Wentia 7:1-116.

PUNT, W., BLACKMORE, S., NILSSON, S. \& LETHOMAS, A. 1999. Glossary of pollen and spore terminology. http:/ /www.biol.ruu.nl/ palaeo/glossary/glos-int.htm (acesso em 18/11/2004).

RAO, A.N. \& LEE, Y.K. 1970. Studies on Singapore pollen. Pacific Science 24:255-268.

ROUBIK, D.W. \& MORENO P., J.E. 1991. Pollen and spores of Barro Colorado Island. Monographs in Systematic Botany 36:1-268.

SALGADO-LABOURIAU, M.L. 1967. Pollen grains of plants of the "Cerrado". XIX- Euphorbiaceae. Anais da Academia Brasileira de Ciências 339:471-490.
SALGADO-LABOURIAU, M.L. 1973. Contribuição à palinologia dos cerrados, Academia Brasileira de Ciências, Rio de Janeiro.

SALGADO-LABOURIAU, M.L., VANZOLINI, P.E. \& MELHEM, T.S. 1965. Variation of polar axes and equatorial diameters in pollen grains of two species of Cassia. Grana 6:166-176.

SILVA, S.A.F. 1966. Notas sôbre a anatomia e pólen de Hibiscus tiliaceus e Hibiscus pernambucensis. Sellowia 18:105-108.

SILVA, F.H.M., OLIVEIRA, P.P. \& SANTOS, F.A.R. 2004. Morfologia polínica de Hibiscus pernambucensis Arruda e Hibiscus tiliaceus L. (Malvaceae). Acta Biologica Leopoldensia 26:203-211.

SILVESTRE, M.S.F. \& CARREIRA, S.M.S. 1985. Flora Polínica da Reserva do Parque Estadual das Fontes do Ipiranga (São Paulo, Brasil). Famílias: 23-Phytolacaceae, 24Nyctaginaceae e 27-Caryophyllaceae. Hoehnea 12:1-4.

SILVESTRE-CAPELATO, M.S.F. \& CORRÊA, A.M.S. 1995. Flora Polínica da Reserva do Parque Estadual das Fontes do Ipiranga (São Paulo, Brasil). Famílias: 11-Aristolochiaceae, 28-Portulacaceae e 86-Thymelaeaceae. Hoehnea 22:159-163.

THANIKAIMONI, G., CARATINI, C., NILSSON, S. \& GRAFSTRÖM, E. 1984. Omniaperturate Euphorbiaceae pollen with striate spines. Bulletin du Jardin Botanique National de Belgique 54:105-125. 